\title{
Stabilizing the Naphthalenediimide Radical within \\ a Tetracationic Cyclophane
}

Tianyu Jiao, ${ }^{\dagger} \star$ Kang Cai,${ }^{\star}$ Jordan N. Nelson,${ }^{\star}$ Yang Jiao, ${ }^{\star}$ Yunyan Qiu, ${ }^{\star}$ Guangcheng Wu ${ }^{\dagger}$ Jiawang Zhou, ${ }^{\star}$ Chuyang Cheng, ${ }^{\star}$ Dengke Shen, ${ }^{\star}$ Yuanning Feng, ${ }^{\star}$ Zhichang Liu, ${ }^{\S}$

Michael R. Wasielewski, ${ }^{*}+$ J. Fraser Stoddart, $*, \star, \|, \uparrow$ and Hao Li ${ }^{*}, \dagger$

${ }^{\dagger}$ Department of Chemistry, Zhejiang University, Hangzhou 310027, P. R. China

${ }^{\ddagger}$ Department of Chemistry, Northwestern University, 2145 Sheridan Road, Evanston, Illinois 60208, USA

${ }^{\S}$ School of Science, Westlake University, 18 Shilongshan Road, Hangzhou 310024, P. R. China

"Institute for Molecular Design and Synthesis, Tianjin University, Tianjin 300072, P. R. China

${ }^{\mathbb{P}}$ School of Chemistry, University of New South Wales, Sydney, NSW 2052, Australia

\section{Supporting Information}

Table of Contents

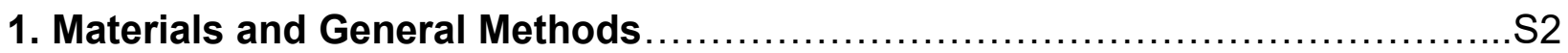

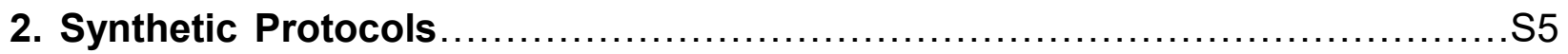

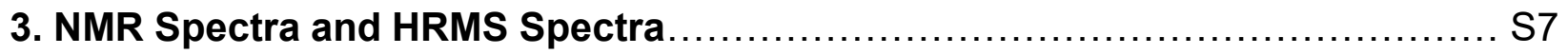

4. Determination of Precise Concentration of Cobaltocene by Titration...S11

5. Binding Studies and Characterization of Host-Guest Complexes.......S12

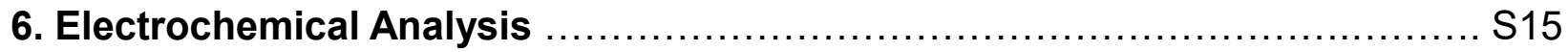

7. UV-Vis Absorption Spectroscopy ….......................................... 116

8. Transient Absorption Analysis ................................................. 17

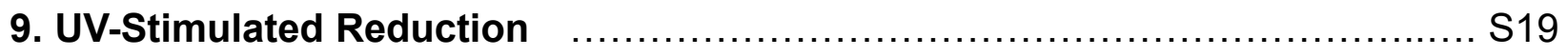

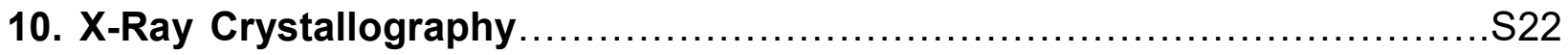

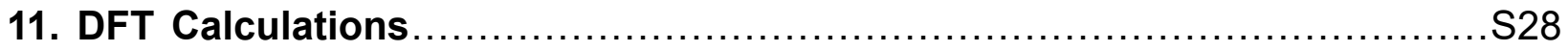

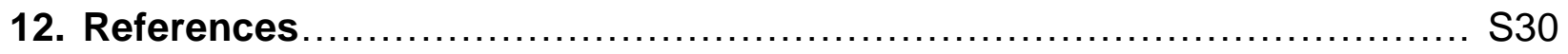

13. Cartesian Coordinates for the Optimized Structures..........................S32 


\section{Materials and General Methods}

Chemicals were purchased as reagent grade and employed without further purification. Compounds ExBox$• 4 \mathrm{PF}_{6},{ }^{1}$ 2-(2-(2-(2-aminoethoxy)ethoxy)ethoxy)ethyl-2-propinylether ${ }^{2}$ and $\mathbf{N D I O H}^{3}$ were prepared according to literature procedures. Thin layer chromatography (TLC) was performed on silica gel 60F254 (E Merck). Column chromatography was carried out on silica gel 60F (Merck 9385, 0.040-0.063 mm). High performance liquid chromatography (HPLC) was performed on a preparative RP-HPLC instrument, using a $\mathrm{C}_{18}$ column (Agilent, $10 \mu \mathrm{m}$ packing, $30 \mathrm{~mm} \times 250 \mathrm{~mm}$ ). The eluents employed were $\mathrm{MeCN}$ and $\mathrm{H}_{2} \mathrm{O}$, both mixed with $0.1 \%(\mathrm{v} / \mathrm{v})$ trifluoroacetic acid (TFA). The detector was set to $\lambda=254 \mathrm{~nm}$. All UV-VisNIR spectra were recorded in $\mathrm{MeCN}$ or $\mathrm{H}_{2} \mathrm{O}$ solvent using a Shimadzu UV-3600 spectrophotometer equipped with a temperature controlled cuvette holder.

Nuclear magnetic resonance (NMR). NMR Spectra were recorded at $298 \mathrm{~K}$ on Bruker Avance 500 and 600 spectrometers, with working frequencies of 500 and $600 \mathrm{MHz}$ for ${ }^{1} \mathrm{H}$, and 125 and $150 \mathrm{MHz}$ for ${ }^{13} \mathrm{C}$ nuclei, respectively. Chemical shifts are reported in ppm relative to the signals corresponding to the residual non-deuterated solvents $\left(\mathrm{CDCl}_{3}: \delta=7.26 \mathrm{ppm}\right.$, $\left.\mathrm{CD}_{3} \mathrm{CN}: \delta=1.94 \mathrm{ppm}, \mathrm{D}_{2} \mathrm{O}: \delta=4.79 \mathrm{ppm}\right)$.

High-resolution mass spectrometry (HRMS). HRMS were measured on an Agilent 6210 Time-of-Flight (TOF) LC-MS, using an ESI source, coupled with Agilent 1100 HPLC stack, using direct infusion $\left(0.6 \mathrm{~mL} \mathrm{~min}^{-1}\right.$ Measurements at X-band $(9.5 \mathrm{GHz})$ were performed with a Bruker Elexsys E580, equipped with a variable Q dielectric resonator (ER-4118X-MD5-W1). 


\section{Cyclic voltammetry (CV) and differential pulse voltammetry (DPV). CV and DPV}

experiments were performed on a Gamry multipurpose instrument interfaced to a PC, using a glassy carbon working electrode $\left(0.071 \mathrm{~cm}^{2}\right.$, Cypress system). The electrode surface was polished routinely with an alumina/water slurry on a felt surface immediately before use. The counter electrode was a $\mathrm{Pt}$ coil and the reference electrode was an $\mathrm{AgCl}$ coated $\mathrm{Ag}$ wire. Samples in MeCN or DMF were prepared using an electrolyte solution of $0.1 \mathrm{M}$ tetrabutylammonium hexafluorophosphate $\left(\mathrm{TBAPF}_{6}\right)$ that was sparged with $\mathrm{N}_{2}$ to remove $\mathrm{O}_{2}$. Samples in water were prepared using an electrolyte solution of $0.1 \mathrm{M}$ sodium chloride that was sparged with $\mathrm{N}_{2}$ to remove $\mathrm{O}_{2}$.

Controlled potential electrolysis (CPE) experiments. A BASi ${ }^{\circledR}$ bulk electrolysis cell was equipped with a reticular vitreous carbon working electrode, a coiled platinum wire auxiliary electrode within a fritted glass chamber and an $\mathrm{Ag} / \mathrm{AgCl}$ reference electrode, and connected to a Gamry multipurpose instrument (Reference 600) interfaced to a PC. The working cell consisted of an aqueous solution of NDIOH $(0.5 \mathrm{mM})$ with $0.1 \mathrm{M}$ sodium chloride maintained under vigorous stirring $(1000 \mathrm{rpm})$ at room temperature, while the auxiliary chamber contained a modified water-soluble ferrocene as sacrificial reductant. The reduction of NDIOH was achieved by applying $-800 \mathrm{mV}$ potential and monitoring the total charge consumed during the process.

UV Irradiation. The UV irradiation process was carried out with an UVGL-58 Handheld UV lamp (P/N 95-0007-05 365nm / 6-Watt / 115V-60Hz / 0.12 Amps). And the samples were contained in a $2 \mathrm{~mm}$ length path cell with a screw-cap under UV irradiation. 
Electron paramagnetic resonance (EPR) spectroscopy. All samples were prepared according to the above procedures in the redox titration and UV-Vis-NIR spectroscopy. The continuous-wave electron paramagnetic resonance (EPR) spectroscopy was performed at Xband (ca. 9.8 GHz) on a Bruker-eleXsys 580 commercial spectrometer equipped with a superhigh-Q resonator (4122-SHQE). Experimental parameters were as follows: modulation frequency of $100 \mathrm{kHz}$, modulation amplitudes of $0.1 \mathrm{mT}$, time constant of 5 seconds, and conversion time of 20 secs. A microwave power of $0.15 \mathrm{~mW}$ was utilized and confirmed to be in the linear regime, precluding saturation of the spectrum.

Photoluminescence spectroscopy. Photoluminescence measurements were performed at room temperature using a HORIBA Nanolog spectrofluorimeter equipped with a 450-W Xe lamp excitation source and a photomultiplier tube (PMT) detector. Absolute photoluminescence quantum yields were determined using an integrating sphere (Horiba Quanta- $\varphi)$.

Femtosecond transient absorption. Femtosecond transient absorption (TA) experiments were performed using an instrument previously described. ${ }^{4}$ The $330 \mathrm{~nm}, \sim 60 \mathrm{fs}$ pump pulses were depolarized using a commercial depolarizer (DPU-25-A, Thorlabs, Inc.) to eliminate any orientational dynamics contributions from the experiment. Spectra were collected on commercial spectrometer (customized Ultrafast Systems, LLC Helios spectrometer). The sample had an optical density of $\sim 0.5$ at $330 \mathrm{~nm}$ in a $2 \mathrm{~mm}$ path length cell and were stirred to avoid localized heating or degradation effects. 


\section{Synthetic Protocols}

\section{Scheme S1. Synthesis of NDIDA}<smiles>O=C1OC(=O)c2ccc3c4c(ccc1c24)C(=O)OC3=O</smiles>
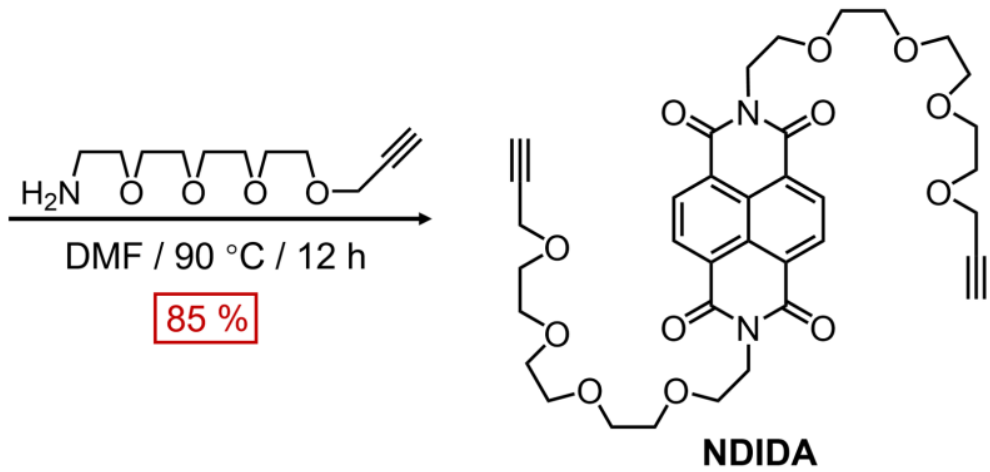

Bis- $N, N$-(2-(2-(2-(2-propynylethoxy)ethoxy)ethoxy)ethyl)naphthalenetetracarboxylic diimide (NDIDA): Naphthalenetetracarboxylic dianydride $(0.54 \mathrm{~g}, 2.01 \mathrm{mmol})$ was suspended in dry DMF (20 mL) and 2-(2-(2-(2-aminoethoxy)ethoxy)ethoxy)ethyl-2-propinylether (1.40 g, 6.04 mmol) was added. The mixture was heated to $90{ }^{\circ} \mathrm{C}$ under $\mathrm{N}_{2}$ and stirred for $12 \mathrm{~h}$. After cooling to room temperature, the solvent was removed under vacuum and the residue was poured into $\mathrm{H}_{2} \mathrm{O}(100 \mathrm{~mL})$ and then extracted with $\mathrm{CH}_{2} \mathrm{Cl}_{2}(3 \times 50 \mathrm{~mL})$. The combined organic extract was washed with $\mathrm{H}_{2} \mathrm{O}(1 \times 50 \mathrm{~mL})$ and brine $(3 \times 80 \mathrm{~mL})$, dried $\mathrm{Na}_{2} \mathrm{SO}_{4}$, and then concentrated to give the crude product. Purification by flash column chromatography (methanol $/ \mathrm{CH}_{2} \mathrm{Cl}_{2}$ (1:20); silica gel) yielded the pure product NDIDA as a yellow solid (1.19 g, $85 \%)$. ${ }^{1} \mathrm{H}$ NMR $\left(500 \mathrm{MHz}, \mathrm{CDCl}_{3}\right): \delta=8.75(\mathrm{~s}, 4 \mathrm{H}), 4.46(\mathrm{t}, J=5.9 \mathrm{~Hz}, 4 \mathrm{H}), 4.18(\mathrm{~d}, J=2.4 \mathrm{~Hz}, 4 \mathrm{H}), 3.85(\mathrm{t}$, $J=5.9 \mathrm{~Hz}, 4 \mathrm{H}), 3.55-3.71(\mathrm{~m}, 24 \mathrm{H}) .{ }^{13} \mathrm{C} \mathrm{NMR}\left(125 \mathrm{MHz}, \mathrm{CDCl}_{3}\right): \delta=163.0,131.1,126.9$, 126.8, 79.8, 74.7, 70.78, 70.73, 70.71, 70.5, 70.3 69.2, 67.9, 58.5, 39.7. HRMS (ESI): $m / z$ calcd for $\mathrm{C}_{36} \mathrm{H}_{46} \mathrm{O}_{12} \mathrm{~N}_{3}\left[M+\mathrm{NH}_{4}\right]^{+}$712.3076, found 712.3083 . 
Scheme S2. Synthesis of ExCat•4PF 6

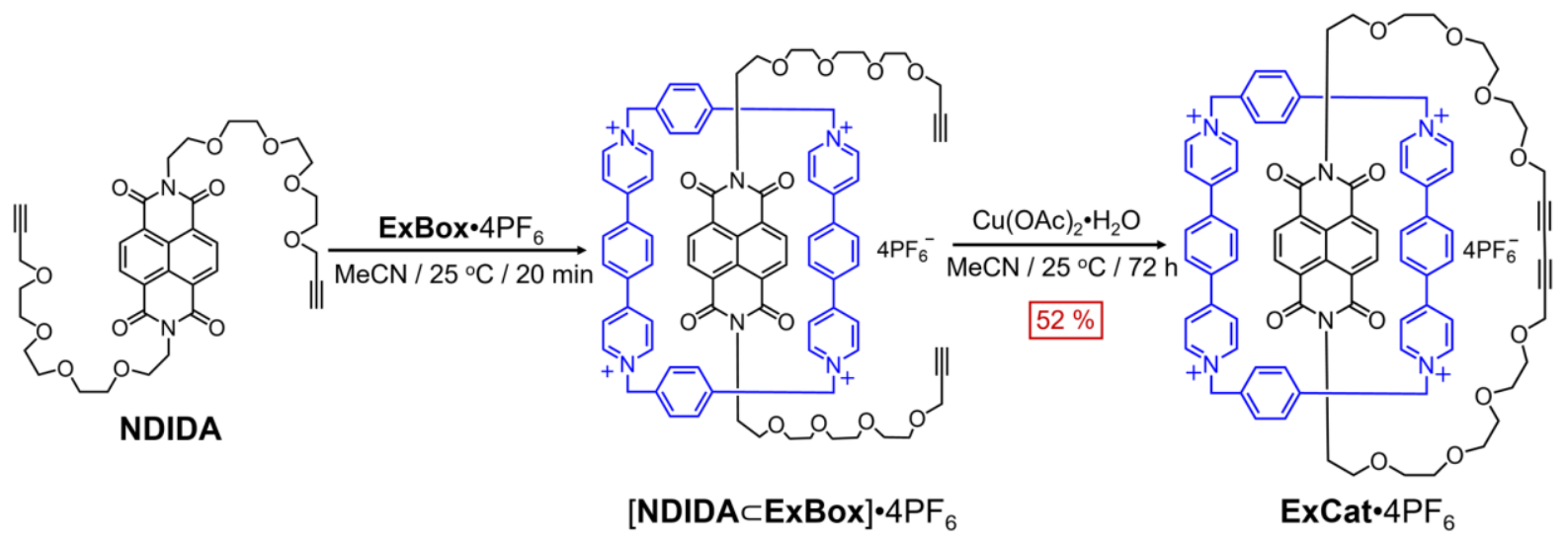

ExCat•4PF6: ExBox•4PF 6 (50.0 mg, $0.04 \mathrm{mmol})$ and NDIDA (83.3 mg, $0.12 \mathrm{mmol})$ were dissolved in $\mathrm{MeCN}(30 \mathrm{~mL})$, and the reaction mixture was stirred at $25{ }^{\circ} \mathrm{C}$ for $20 \mathrm{~min}$. $\mathrm{Cu}(\mathrm{OAc})_{2} \bullet \mathrm{H}_{2} \mathrm{O}(36.0 \mathrm{mg}, 0.20 \mathrm{mmol})$ was added to the above solution. The reaction mixture was stirred for a further $72 \mathrm{~h}$ at $25^{\circ} \mathrm{C}$, during which time the color of the solution changed from blue to green. The solvent was removed under vacuum, and the crude solid was subjected to column chromatography $\left(1 \% \mathrm{NH}_{4} \mathrm{PF}_{6}\right.$ in $\mathrm{MeCN}(\mathrm{w} / \mathrm{v})$; silica gel). The pure fractions were combined, concentrated under vacuum, reprecipitated in $\mathrm{H}_{2} \mathrm{O}$, filtered off and washed with $\mathrm{H}_{2} \mathrm{O}(50 \mathrm{~mL})$ to afford crude product as white solid. The crude solid material was analyzed and showed to contained ExBox $\bullet 4 \mathrm{PF}_{6}$ and the desired ExCat•4PF 6 . In order to isolate pure ExCat $4 \mathrm{PF}_{6}$, the above crude product was subjected to preparative reverse-phase HPLC $\left(\mathrm{C}_{18}\right.$ column), starting with $\mathrm{H}_{2} \mathrm{O}$ containing $0.1 \%$ TFA as eluent, and increasing to $50 \%$ of $\mathrm{MeCN}$ / $0.1 \%$ TFA. The combined fractions were concentrated under vacuum and treated with saturated aqueous $\mathrm{NH}_{4} \mathrm{PF}_{6}$ to furnish pure ExCat•4PF $6(40.1 \mathrm{mg}, 52 \%)$ as a white solid. ${ }^{1} \mathrm{H}$ $\operatorname{NMR}\left(600 \mathrm{MHz}, \mathrm{CD}_{3} \mathrm{CN}\right): \delta=8.80(\mathrm{~d}, J=7.2 \mathrm{~Hz}, 8 \mathrm{H}), 7.84(\mathrm{~d}, J=7.2 \mathrm{~Hz}, 8 \mathrm{H}), 7.82(\mathrm{~s}, 8 \mathrm{H})$, $7.16(\mathrm{~s}, 8 \mathrm{H}), 7.13(\mathrm{~s}, 4 \mathrm{H}), 5.74(\mathrm{~s}, 8 \mathrm{H}), 4.06(\mathrm{t}, J=5.1 \mathrm{~Hz}, 4 \mathrm{H}), 3.88(\mathrm{~s}, 4 \mathrm{H}), 3.82-3.79(\mathrm{~m}$, 4H), 3.75-3.71 (m, 8H), 3.61-3.59 (m, 4H), 3.49-3.46 (m, 4H), 3.39-3.36 (m, 4H), 3.27-3.25 (m, 4H). ${ }^{13} \mathrm{C}$ NMR $\left(125 \mathrm{MHz}, \mathrm{CD}_{3} \mathrm{CN}\right): \delta=162.3,153.3,145.3,137.3,135.5,131.4,130.6$, 128.6, 125.7, 126.0, 125.6, 76.9, 70.9, 70.8, 70.7, 70.6, 70.1, 69.7, 68.0, 65.0, 59.0, 40.6, 30.3. HRMS (ESI): $m / z$ calcd for $\mathrm{C}_{84} \mathrm{H}_{80} \mathrm{O}_{12} \mathrm{~F}_{12} \mathrm{~N}_{6} \mathrm{P}_{2}\left[M-2 \mathrm{PF}_{6}\right]^{2+} 827.2553$, found 827.2576; calcd for $\mathrm{C}_{84} \mathrm{H}_{80} \mathrm{O}_{12} \mathrm{~F}_{6} \mathrm{~N}_{6} \mathrm{P}_{1}\left[M-3 \mathrm{PF}_{6}\right]^{3+} 503.1820$, found 503.1839; calcd for $\mathrm{C}_{84} \mathrm{H}_{80} \mathrm{O}_{12} \mathrm{~N}_{6}[M-$ $\left.4 \mathrm{PF}_{6}\right]^{4+} 341.1453$, found 341.1474 . 
3. NMR Spectra and HRMS Spectra

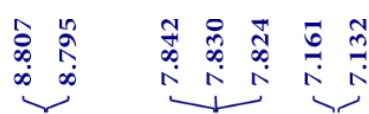

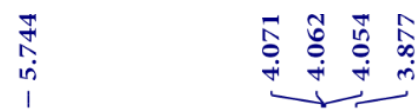
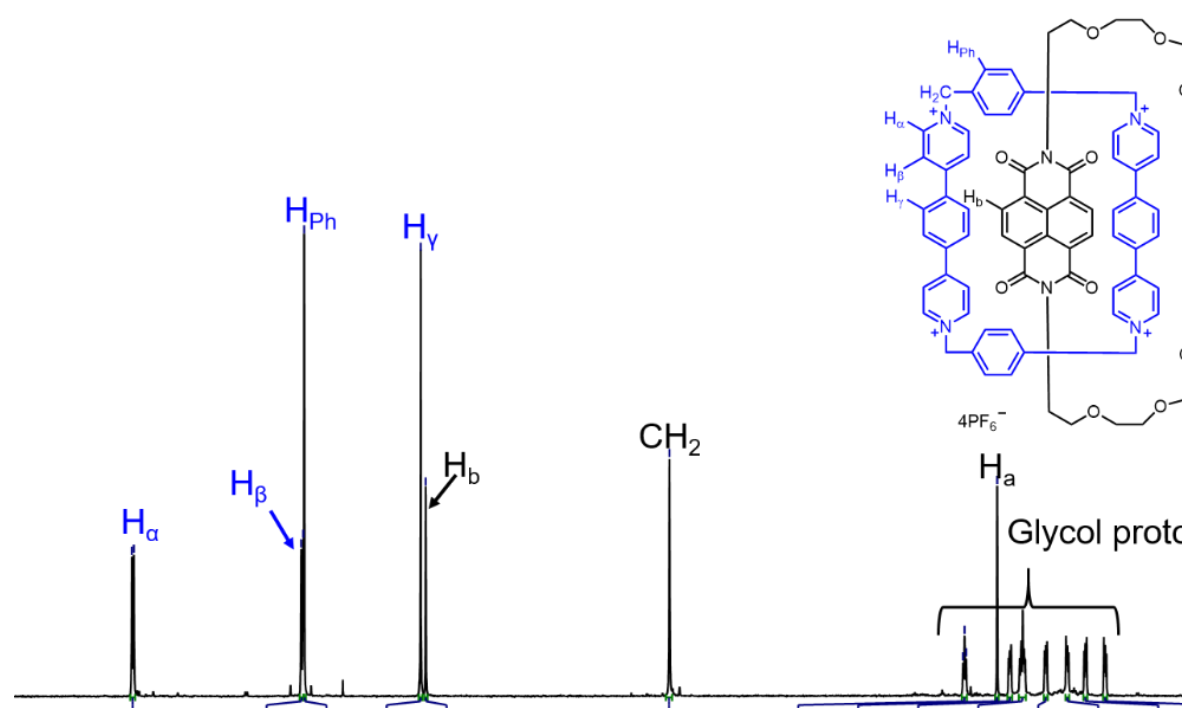

$4 \mathrm{PF}_{6}{ }^{-}$

$\mathrm{CHD}_{2} \mathrm{CN}$

$8.27 \quad 8.047 .988 .134 .00$

$8.17 \quad 4.224 .144 .248 .664 .364 .554 .234 .14$

\begin{tabular}{|c|c|c|c|c|c|c|c|}
\hline 9.0 & 8.0 & 7.0 & 6.0 & $\begin{array}{l}5.0 \\
m\end{array}$ & 4.0 & 3.0 & 2.0 \\
\hline
\end{tabular}

Figure S1. ${ }^{1} \mathrm{H}$ NMR Spectrum (600 MHZ, $\left.\mathrm{CD}_{3} \mathrm{CN}, 298 \mathrm{~K}\right)$ of ExCat•4PF6

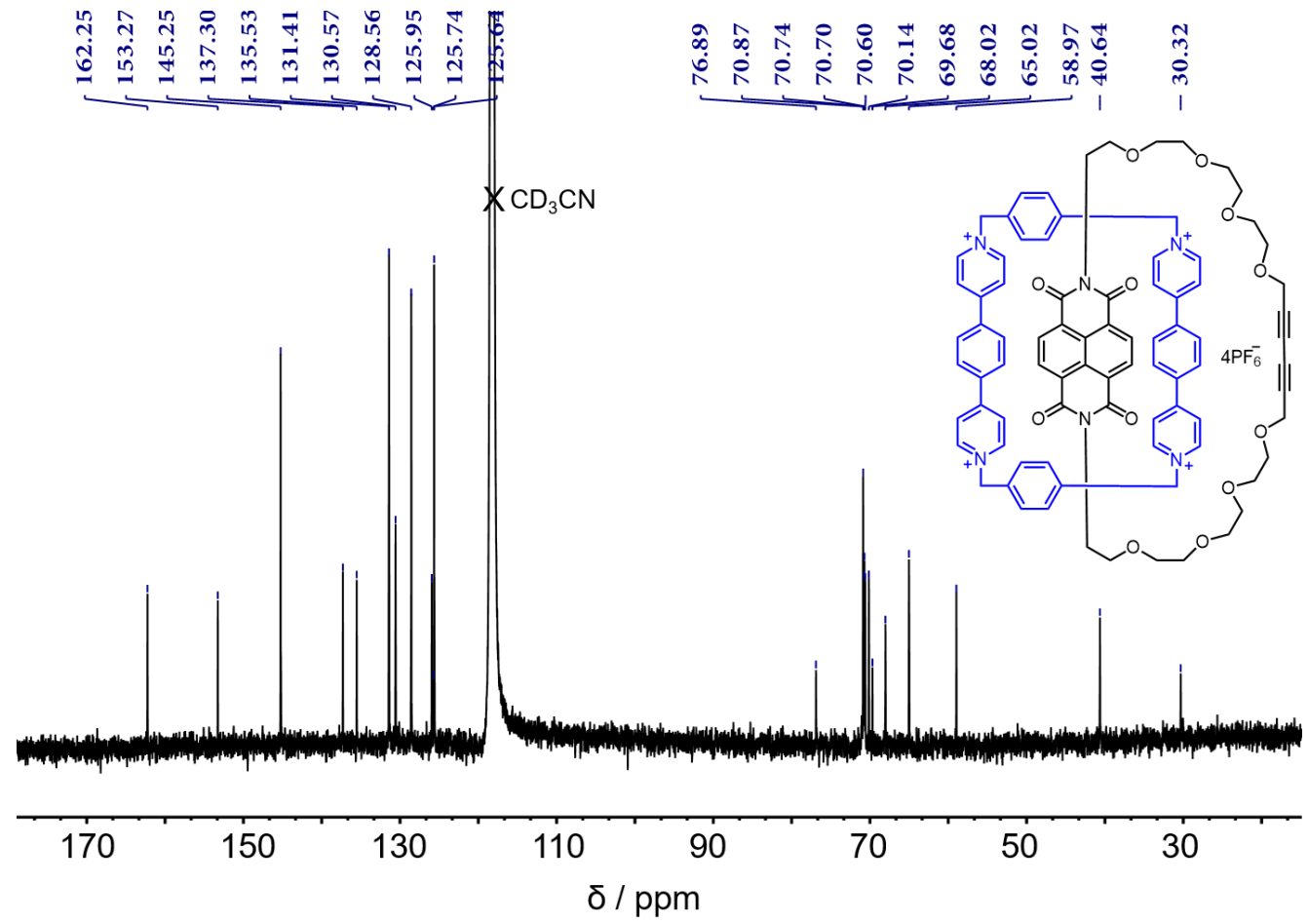

Figure S2. ${ }^{13} \mathrm{C}$ NMR Spectrum (125 MHZ, $\mathrm{CD}_{3} \mathrm{CN}, 298 \mathrm{~K}$ ) of ExCat॰4PF 6 


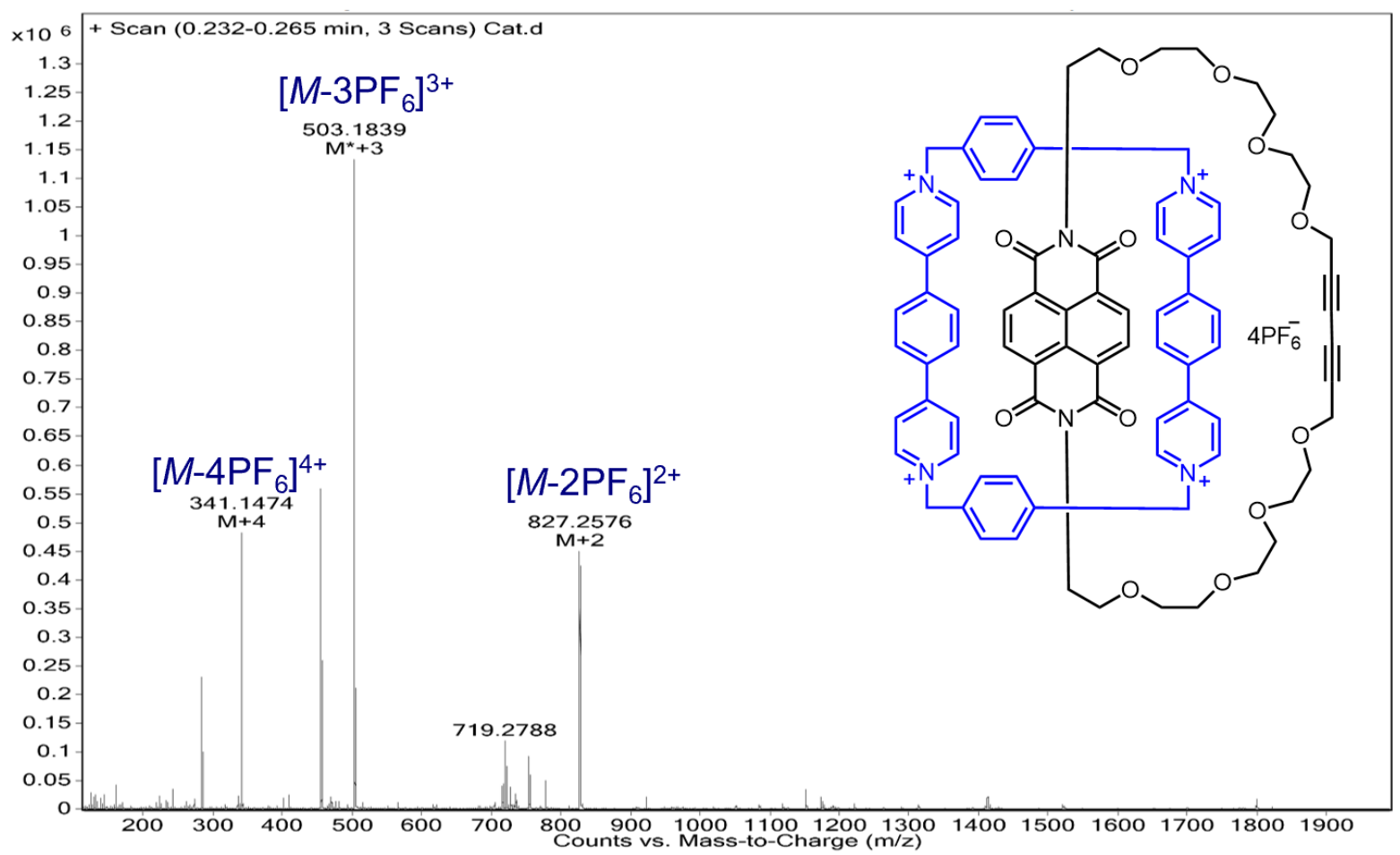

Figure S3. ESI-MS of ExCat॰4PF6. The signals labelled in the spectra correspond to the loss of 2,3 or 4 of $\mathrm{PF}_{6}{ }^{-}$counterions

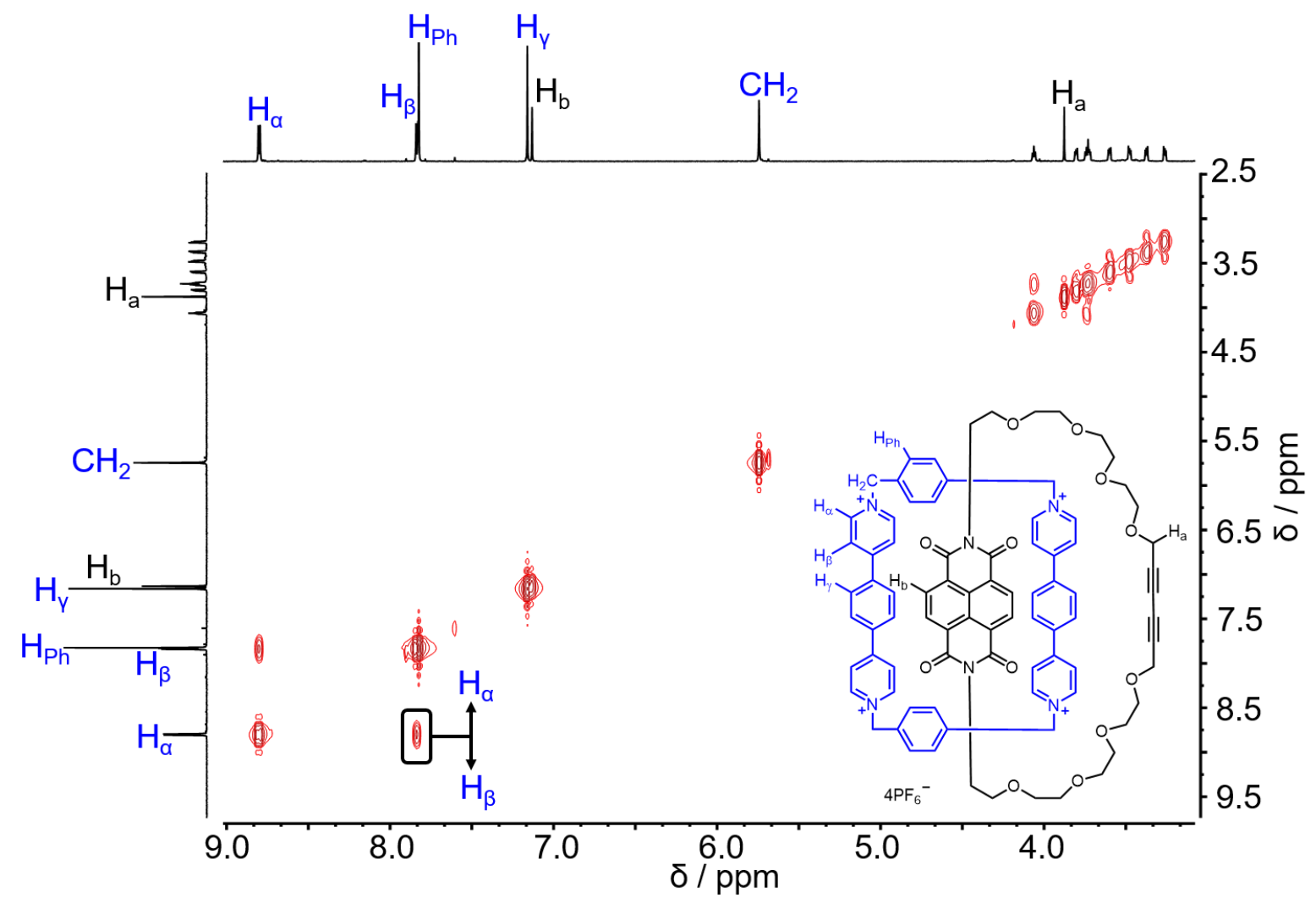

Figure S4. ${ }^{1} \mathrm{H}-{ }^{1} \mathrm{H}$ Gradient-selected double-quantum filtered phase-sensitive COSY spectrum of ExCat•4PF $6\left(500 \mathrm{MHz}, \mathrm{CD}_{3} \mathrm{CN}, 298 \mathrm{~K}\right)$. Key correlation peaks are labeled in the spectrum 


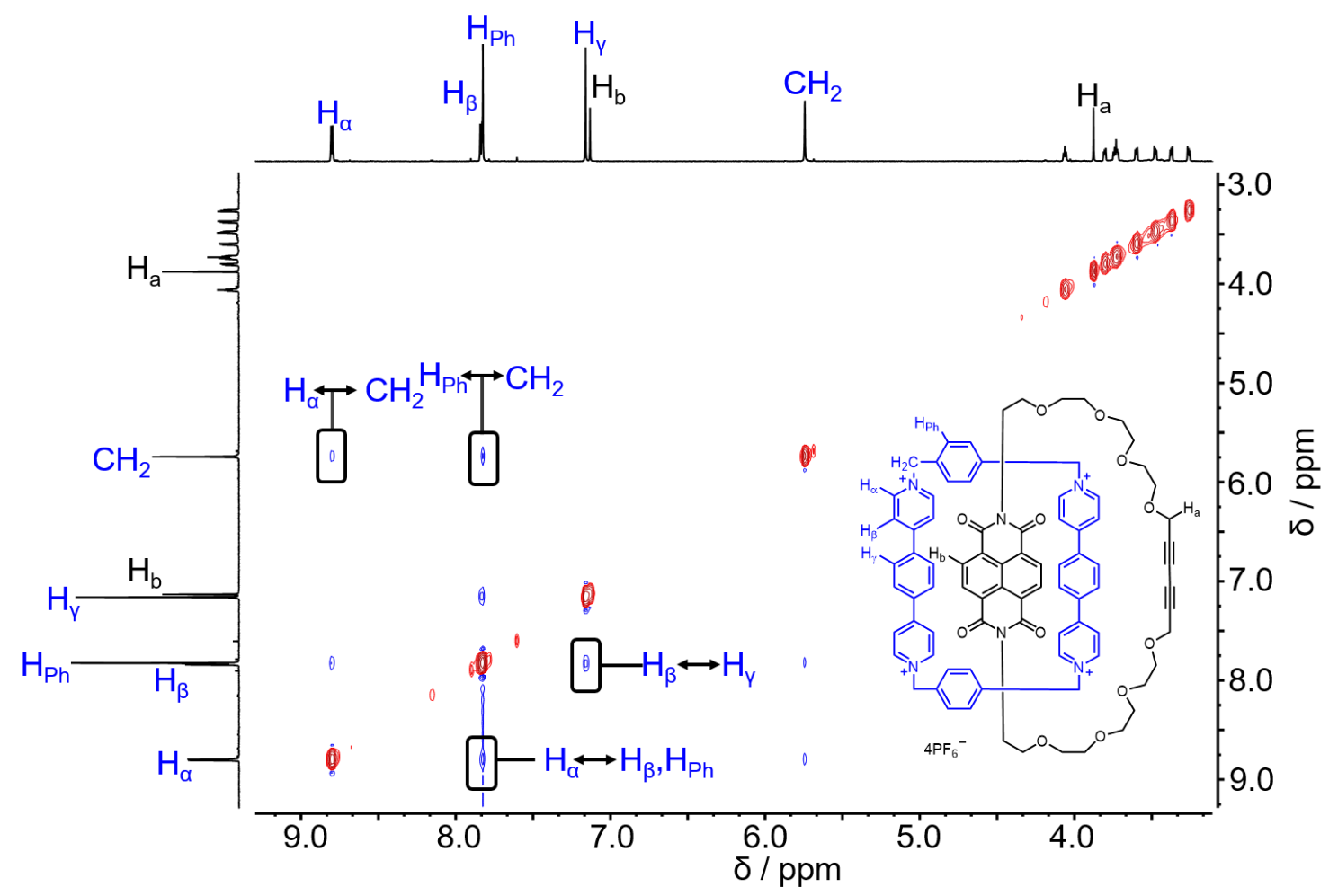

Figure S5. ${ }^{1} \mathrm{H}-{ }^{1} \mathrm{H}$ NOESY spectrum of ExCat•4PF6 (500 MHz, CD 3 CN, 298K). Through-space proton couplings are labeled in the spectrum

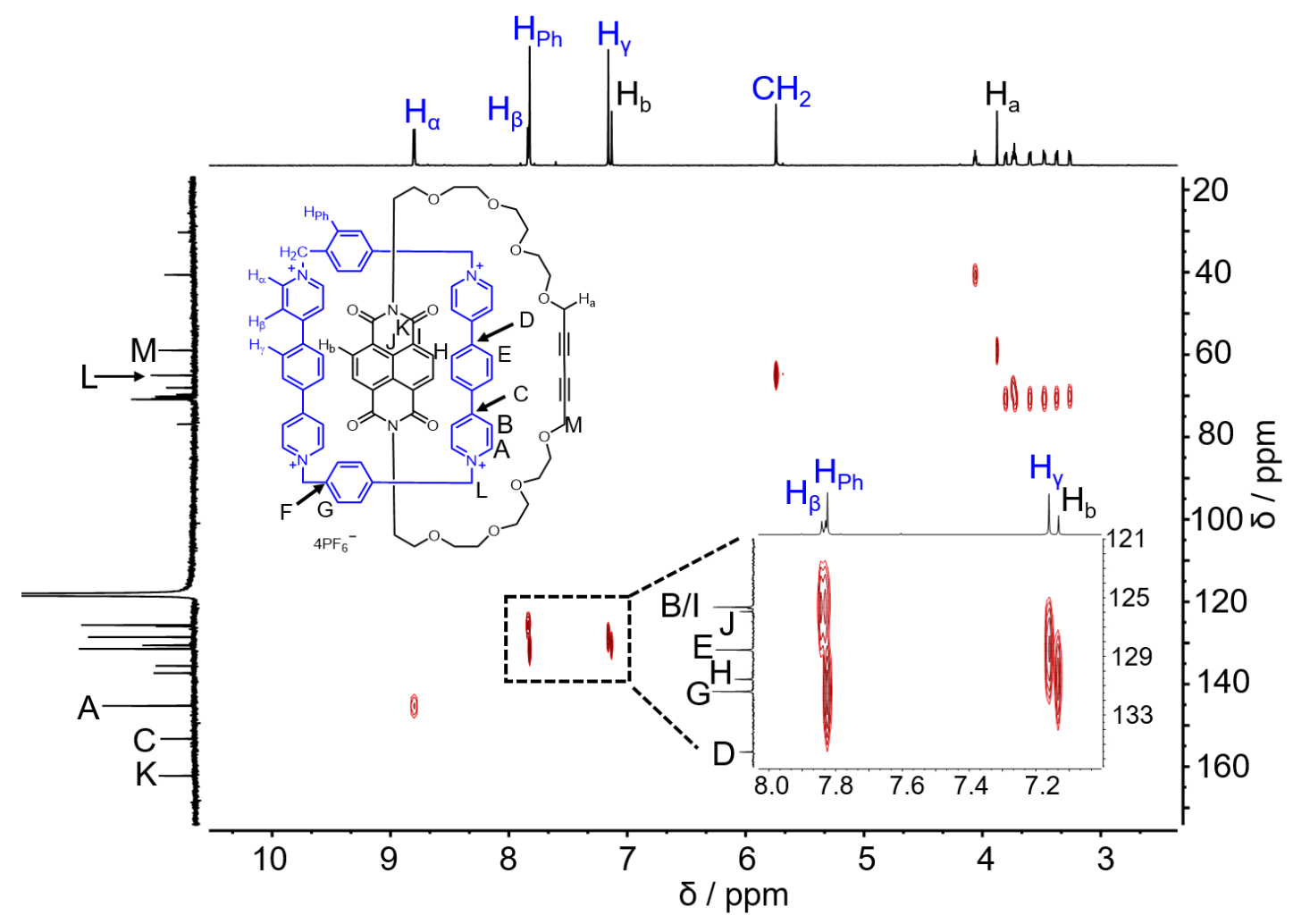

Figure S6. Part of the annotated ${ }^{1} \mathrm{H}-{ }^{13} \mathrm{C}$ Heteronuclear Single Quantum Coherence (HSQC) spectrum (125 MHz, CD ${ }_{3} \mathrm{CN}, 298 \mathrm{~K}$ ) of ExCat॰4PF 6 


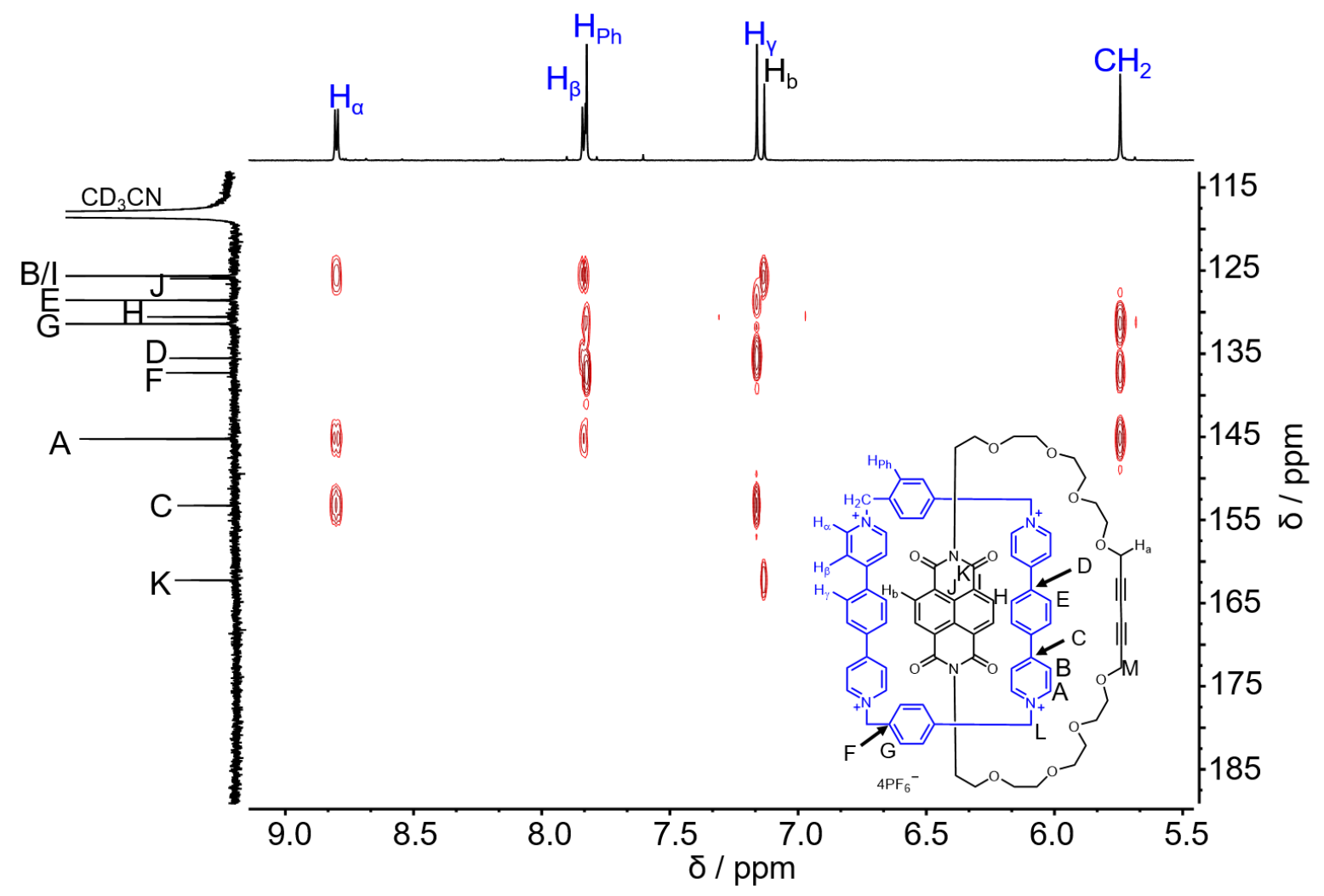

Figure S7. Part of the annotated ${ }^{1} \mathrm{H}-{ }^{13} \mathrm{C}$ Heteronuclear Multiple Bond Coherence (HMBC) spectrum (125 MHz, $\mathrm{CD}_{3} \mathrm{CN}, 298 \mathrm{~K}$ ) of ExCat॰4PF 6 


\section{Determination of Precise Concentration of Cobaltocene by UV-Vis Titration}

The precise concentration of cobaltocene $\left(\mathrm{CoCp}_{2}\right)$ in the stock solution in $\mathrm{MeCN}$ was determined by UV-Vis titration, as the result of its uncertainty caused by air- and moisturesensitivity. Methyl viologen $\left(\mathbf{M V} \cdot 2 \mathrm{PF}_{6}\right)$ can be reduced as its cationic radical state after acquiring 1 equiv electron from $\mathrm{CoCp}_{2}$, thus it was employed to determine the precise concentration of $\mathrm{CoCp}_{2}$ stock solution in $\mathrm{MeCN}$. In a typical titration experiment, a $\mathbf{M V} \cdot 2 \mathrm{PF}_{6}$ solution in $\mathrm{MeCN}\left(5.0 \times 10^{-4} \mathrm{M}\right)$ was prepared as the standard with precise concentration by weight measurement. Then $\mathrm{CoCp}_{2}$ stock solution in $\mathrm{MeCN}$ (about $4 \times 10^{-3} \mathrm{M}$ ) was carefully added to the above $\mathbf{M V} \cdot 2 \mathrm{PF}_{6}$ solution $(600 \mu \mathrm{L})$ until that the UV-Vis absorption spectra showed the peak of $\mathbf{M V}^{+\bullet}$ at $605 \mathrm{~nm}$ reached saturation. Thus, the precise concentration of $\mathrm{CoCp} 2$ stock solution was obtained by the following calculation, $\left[\mathrm{CoCp}_{2}\right]=\left[\mathbf{M V}^{2+}\right] \times V_{\mathbf{M v}}{ }^{2+} /$ $V_{\mathrm{CoCp} 2}=\left(5.0 \times 10^{-4} \mathrm{M}\right) \times(600 \mu \mathrm{L}) /(67 \mu \mathrm{L})=4.5 \times 10^{-3} \mathrm{M}$.

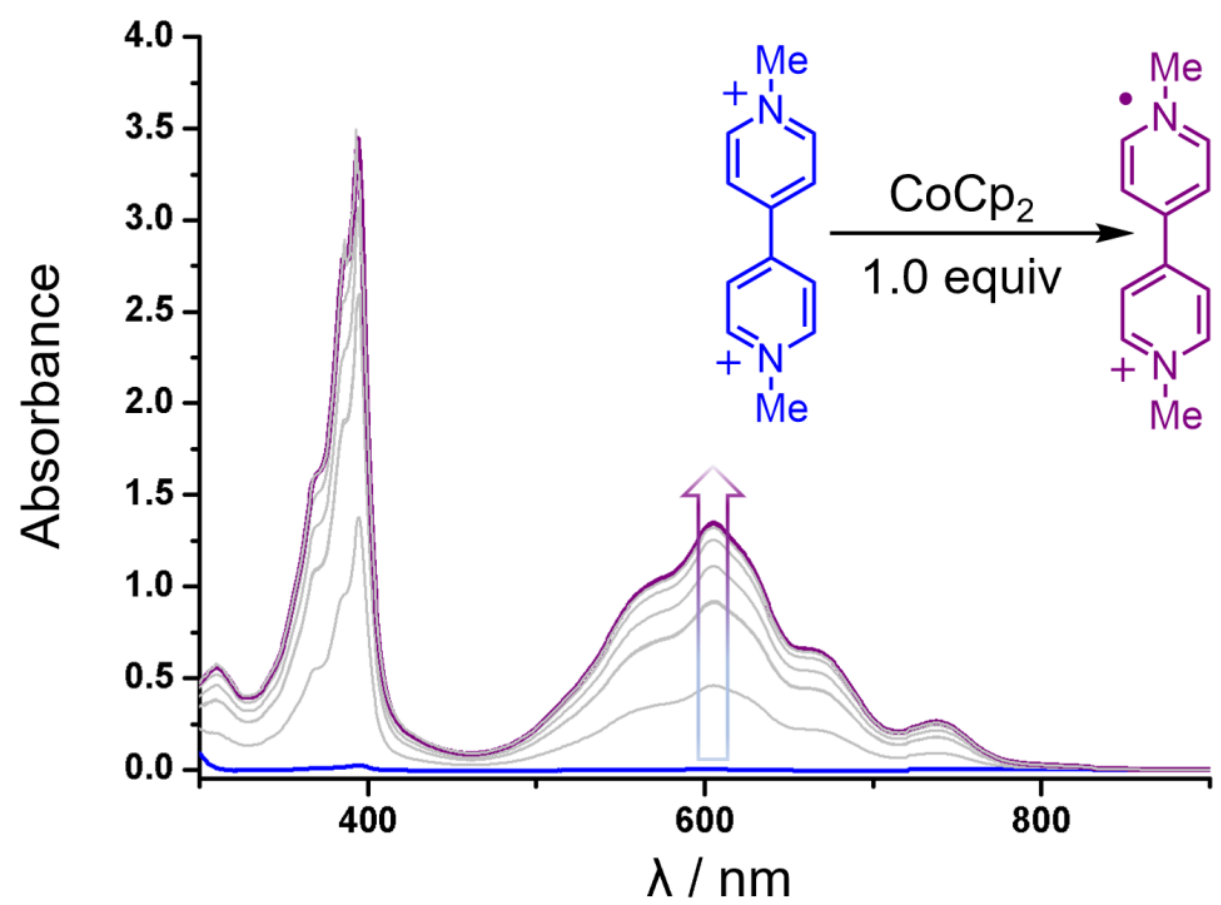

Figure S8. UV-Vis absorption spectra of $\mathbf{M V} \cdot 2 \mathrm{PF}_{6}(0.50 \mathrm{mM}$ in $\mathrm{MeCN})$ before (blue trace) and after (grey and purple traces) adding $\mathrm{CoCp}_{2}$ stock solution. All measurements were recorded at $298 \mathrm{~K}$ in a $2 \mathrm{~mm}$ path length cell equipped with a screw-cap and additions of titrant were conducted using a glass microliter syringe inside of a $\mathrm{N}_{2}$ glovebox 


\section{Binding Studies and Characterization of Host-Guest Complex}
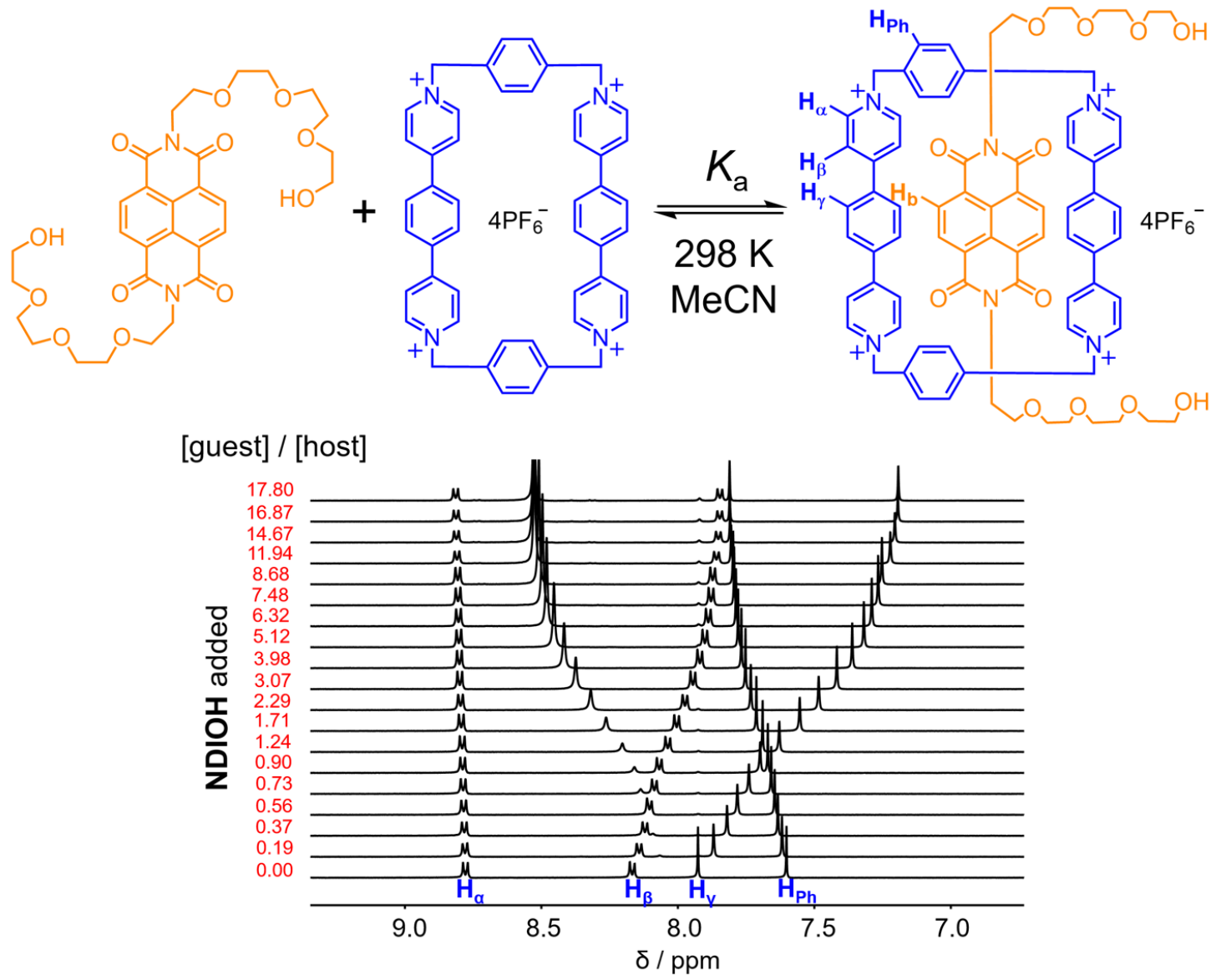

Figure S9. ${ }^{1} \mathrm{H}$ NMR Spectra $\left(600 \mathrm{MHz}, 298 \mathrm{~K}, \mathrm{CD}_{3} \mathrm{CN}\right)$ of ExBox॰4PF $6\left(1.33 \times 10^{-3}\right.$ $\mathrm{M})$ before (bottom) and after titrating different equiv of $\mathrm{NDIOH}$

a)

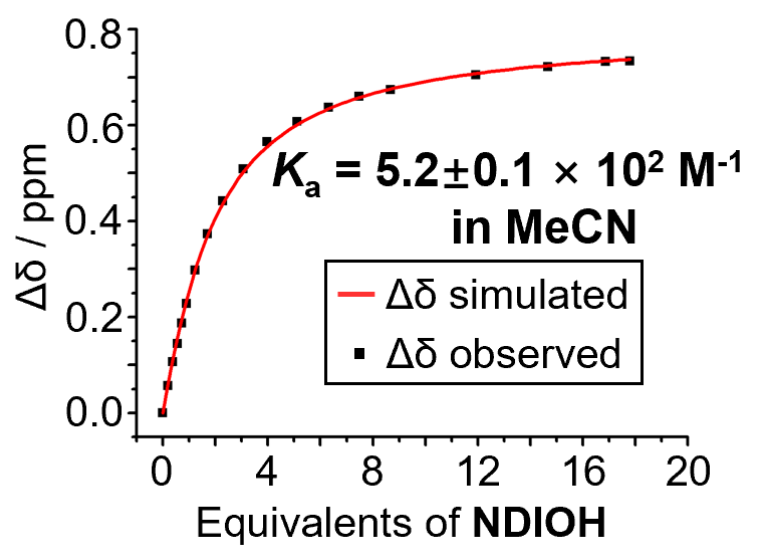

b)

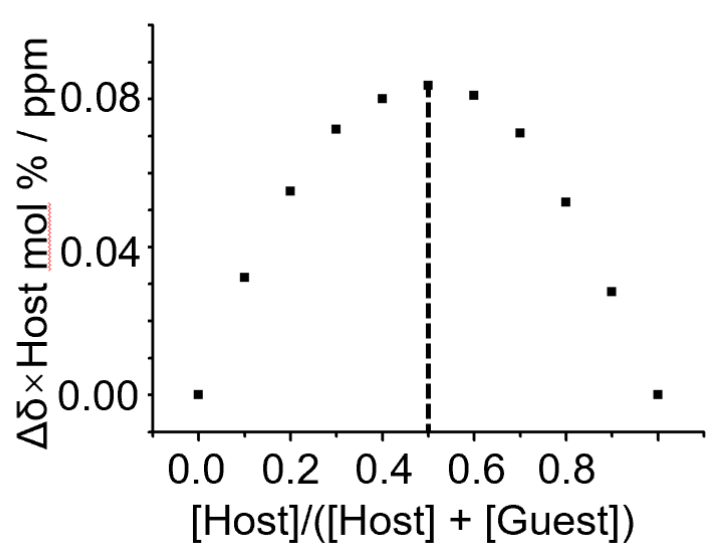

Figure S10. a) Observed (dot) and calculated (red line) plots of the resonance shifts of the proton $\mathrm{H}_{\mathrm{Y}}$ based on the corresponding ${ }^{1} \mathrm{H}$ NMR spectra in Figure S9. b) Job-plot analysis of binding complex between $\mathrm{ExBox}^{4+}$ and NDIOH. Job-plot corresponding to the binding between $\mathrm{ExBox}^{4+}$ and $\mathrm{NDIOH}$ at different molarity ratio. $\left[\mathrm{ExBox}^{4+}\right]+$ $[\mathrm{NDIOH}]=1.0 \mathrm{mM}$. The value distribution indicates a 1:1 (host:guest) binding stoichiometry 


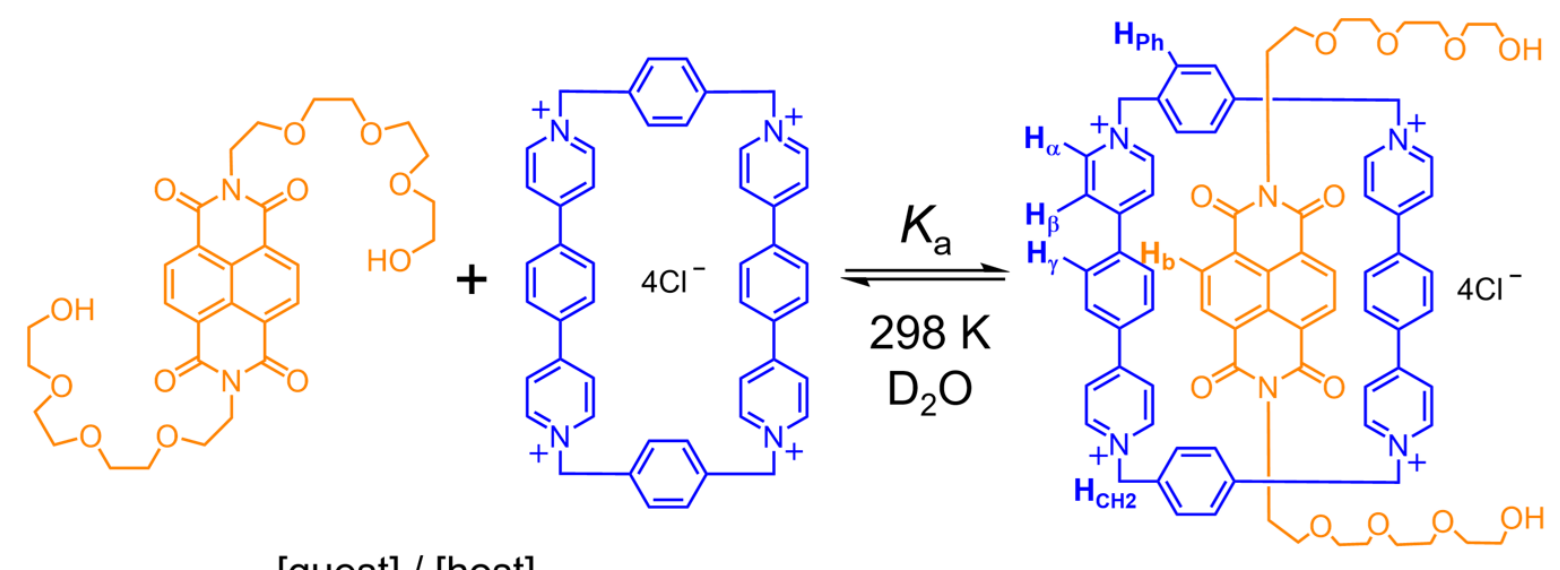

[guest] / [host]

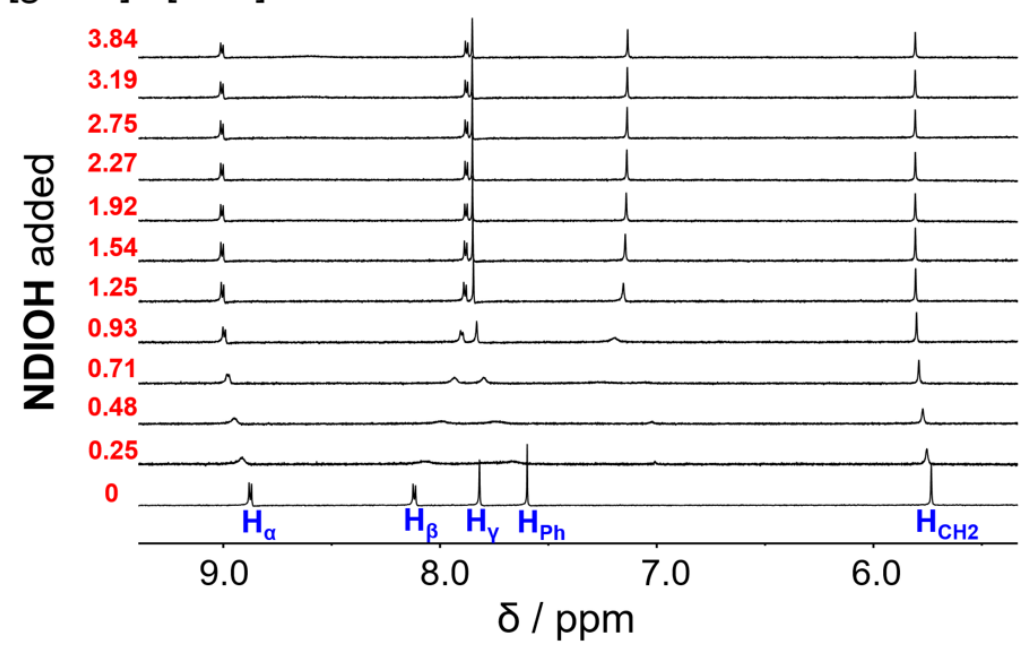

Figure S11. ${ }^{1} \mathrm{H}$ NMR Spectra $\left(600 \mathrm{MHz}, 298 \mathrm{~K}, \mathrm{D}_{2} \mathrm{O}\right)$ of ExBox•4Cl before (bottom) and after adding different amount of NDIOH. The concentration of ExBox$\bullet 4 \mathrm{Cl}$ was constant for all spectra, namely $2.5 \times 10^{-4} \mathrm{M}$

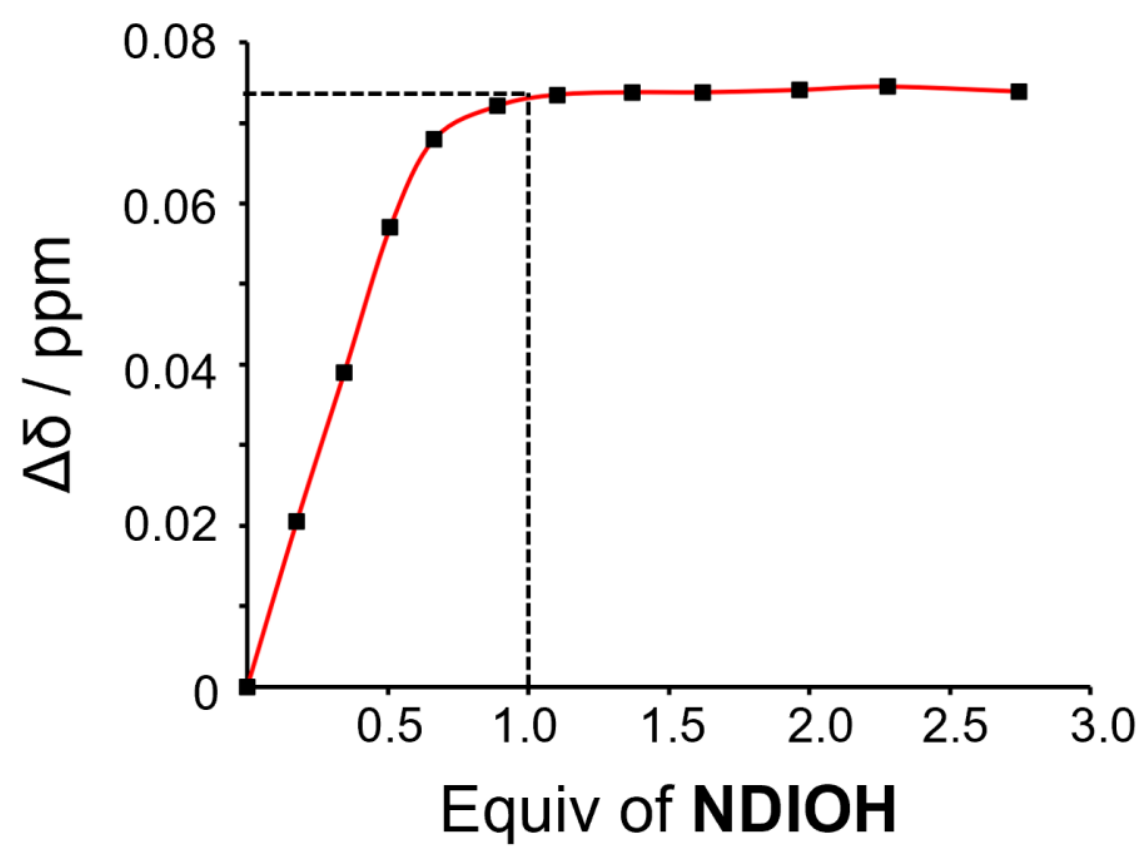

Figure S12. Observed (dot) and calculated (red line) plots of the resonance shifts of the proton $\mathrm{H}_{\mathrm{CH}}$ based on the corresponding ${ }^{1} \mathrm{H}$ NMR spectra in Figure S11 
a)
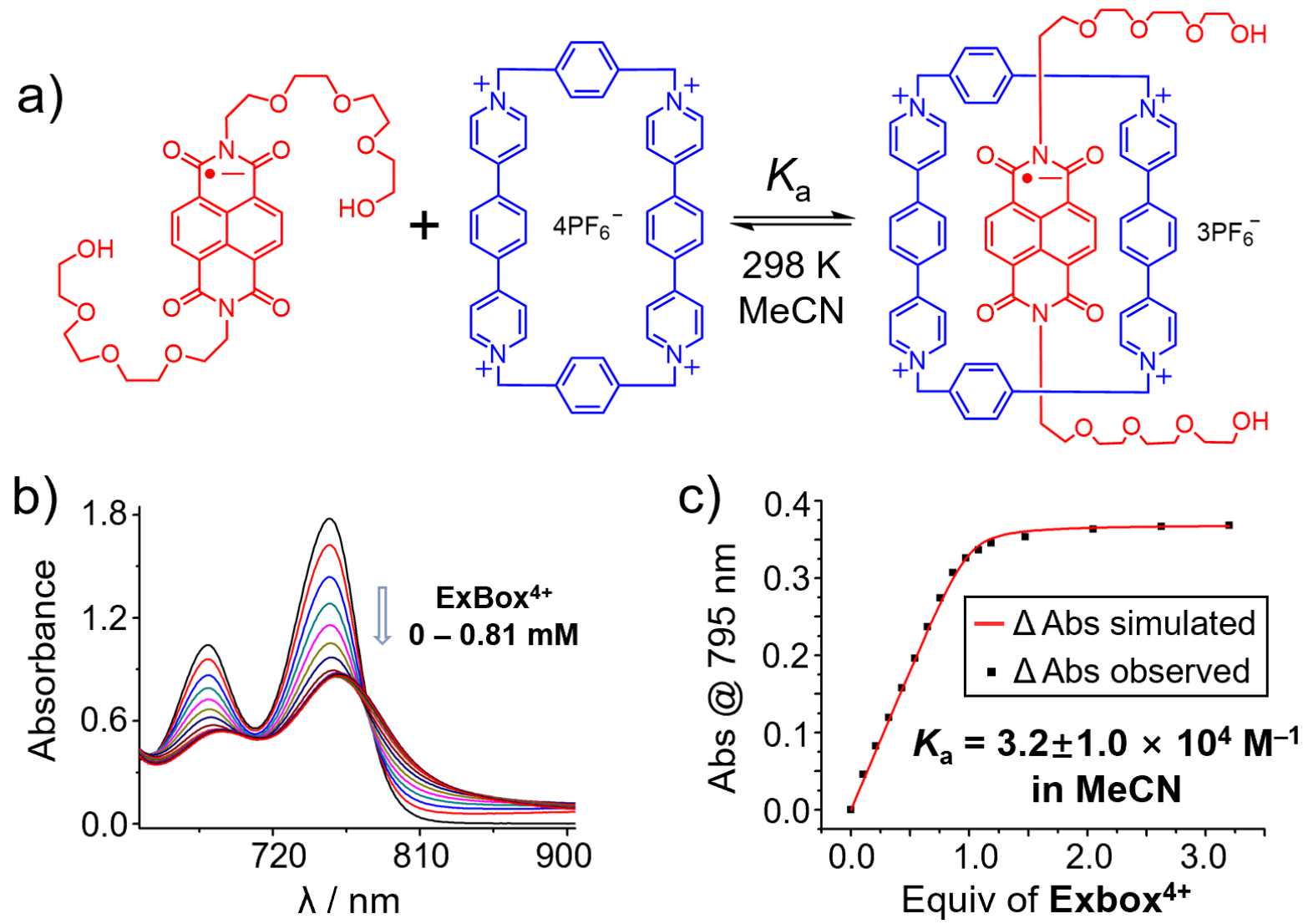

Figure S13. a) 1:1 Binding behavior between ExBox ${ }^{4+}$ and $\mathrm{NDIOH}^{--}$in $\mathrm{MeCN}$. b) VisNIR absorption spectra of $\mathrm{NDIOH}^{--}$before (top) and after titrating different amount of ExBox ${ }^{4+}$. The concentration of $\mathrm{NDIOH}^{--}$is constant for all spectra, i.e., $0.30 \mathrm{mM}$. All measurements were recorded at $298 \mathrm{~K}$ in a $1 \mathrm{~cm}$ path length cell equipped with a screw-cap and additions of titrant were conducted using a glass microliter syringe inside of a $\mathrm{N}_{2}$ glovebox. c) Observed (dot) and calculated (red line) plots of the change in absorption at $795 \mathrm{~nm}$ with titration based on the corresponding spectra in Figure $\mathrm{S} 13 \mathrm{~b}$ 


\section{Electrochemical Analysis}
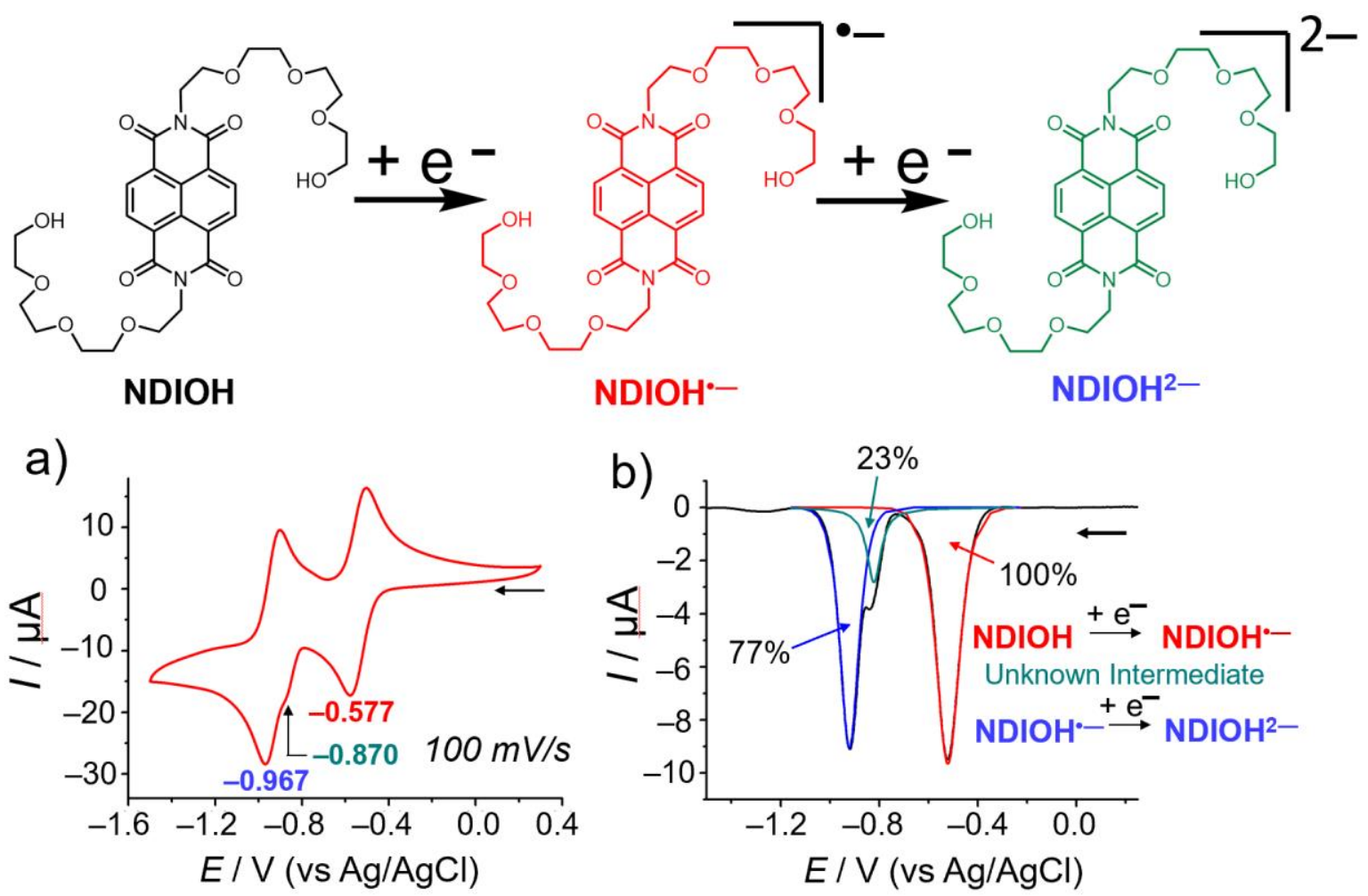

Figure S14. a) Cyclic voltammetry of $\mathrm{NDIOH}$ shows two single-electron redox processes, corresponding to the reduction of the $\mathbf{N D I O H}$ from neural state to single radical anion $\mathrm{NDIOH}^{--}$at $-0.577 \mathrm{~V}$ and dianion $\mathrm{NDIOH}^{2-}$ at $-0.967 \mathrm{~V}$. A glass carbon working electrode, a platinum counter electrode, and a $\mathrm{Ag} / \mathrm{AgCl}$ reference electrode were used in the characterization of $1 \mathrm{mM} \mathrm{MeCN}$ solutions of $\mathbf{N D I O H}$ at $298 \mathrm{~K}$ with 0.1 $\mathrm{M} \mathrm{TBAPF}_{6}$ serving as the electrolyte. A scan rate of $100 \mathrm{mVs}^{-1}$ was used for this analysis. b) Differential Pulse Voltammetry (DPV) of NDIOH (10 mV s$~^{-1}$ scan rate / 25 $\mathrm{mV}$ pulse/0.1 ms pulse time / $1 \mathrm{mV}$ step size / $1 \mathrm{~s}$ sample period / $1 \mathrm{mM}$ of NDIOH / $\left.\mathrm{MeCN} / 298 \mathrm{~K} / 0.1 \mathrm{M} \mathrm{TBAPF}_{6}\right)$ 


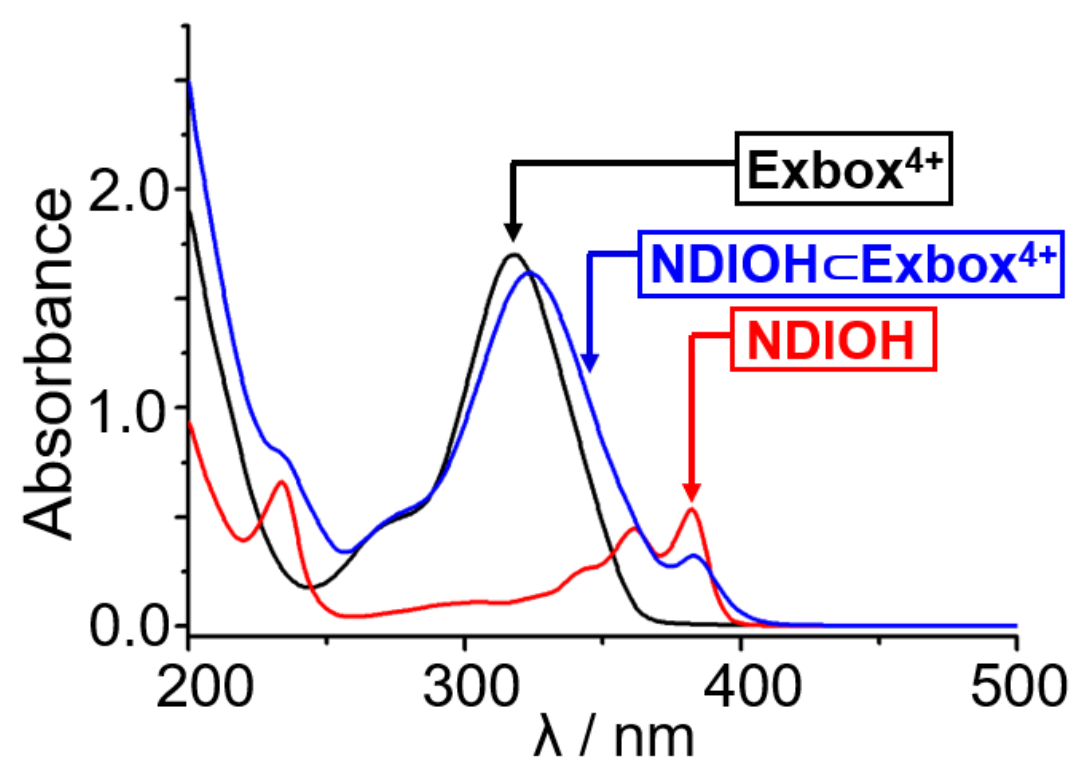

Figure S15. UV-Vis Absorption spectra of NDIOH, ExBox $4 \mathrm{Cl}$ and the 1:1 mixture of $\mathrm{NDIOH}$ and ExBox$\cdot 4 \mathrm{Cl}$. All the spectra were recorded at $298 \mathrm{~K}$ in $\mathrm{H}_{2} \mathrm{O}(0.15 \mathrm{mM})$

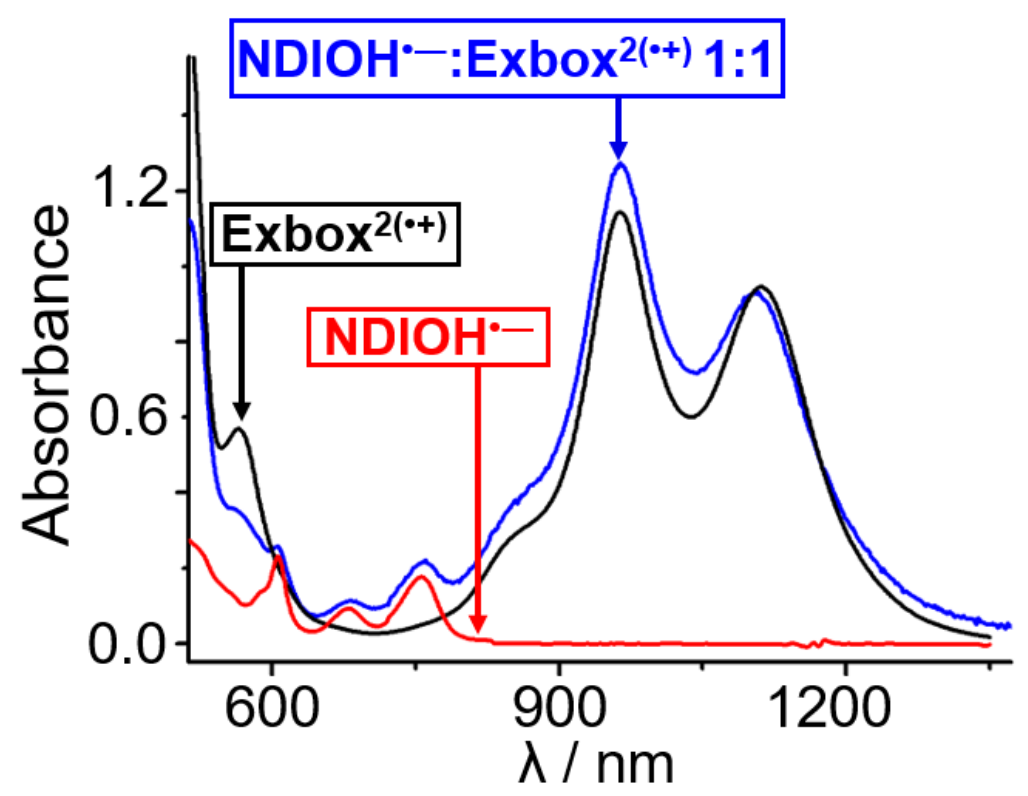

Figure S16. UV-Vis Absorption spectra of $\mathrm{NDIOH}^{--}$, ExBox ${ }^{2(+) \cdot} 2 \mathrm{PF}_{6}$ and the $1: 1$

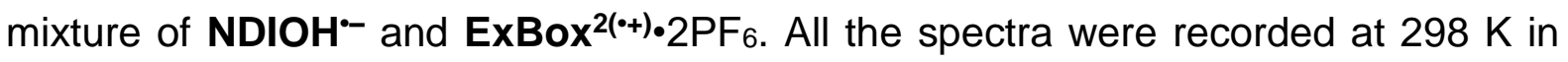
$\mathrm{MeCN}(0.15 \mathrm{mM})$ 


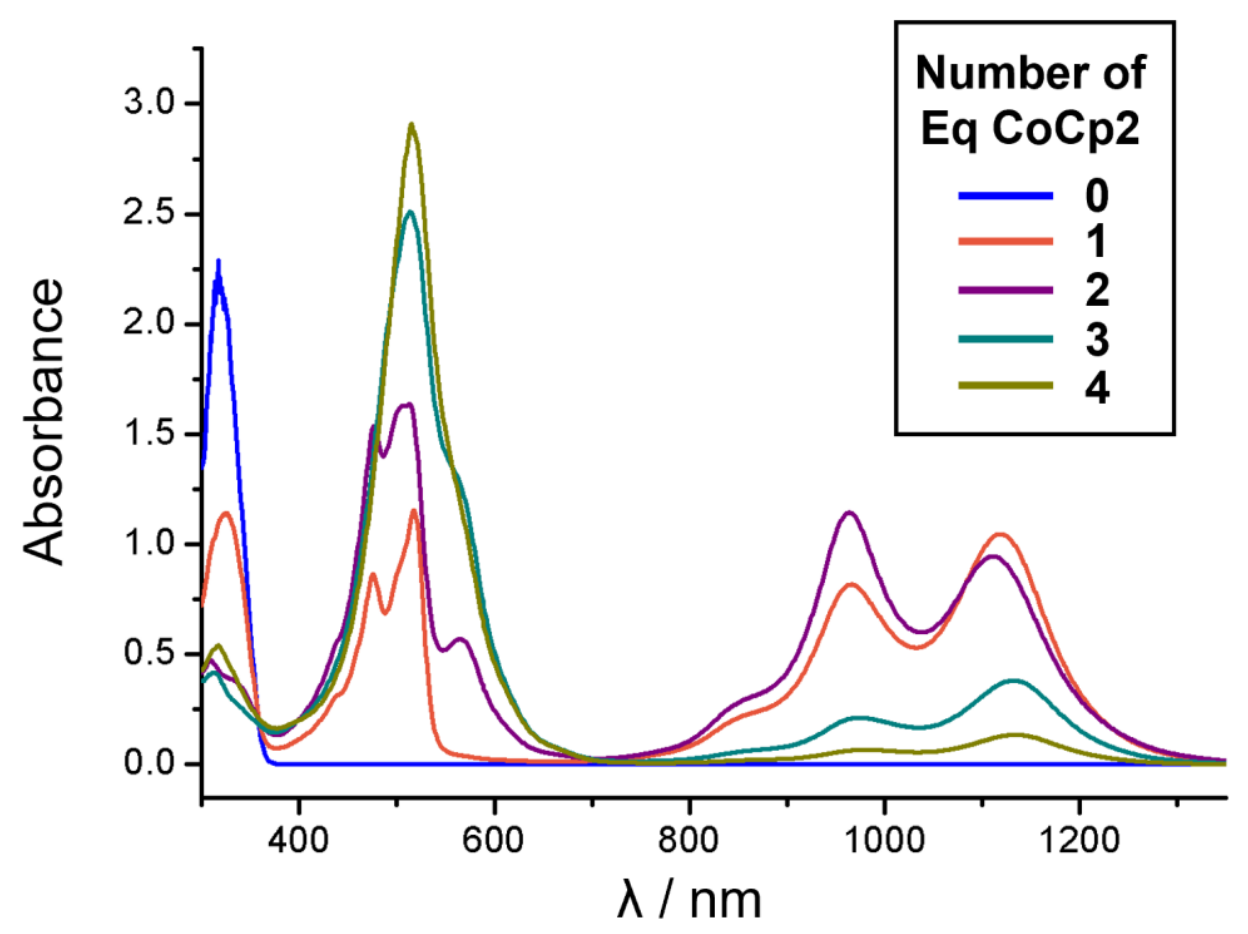

Figure S17. UV-Vis-NIR Absorption spectra of ExBox ${ }^{4+}$ upon reduction into the +4 , $+3,+2,+1$, and 0 reduction states by adding $0,1,2,3$, and 4 equiv CoCp2. All the spectra were recorded at $298 \mathrm{~K}$ in $\mathrm{MeCN}(0.15 \mathrm{mM})$

\section{Transient Absorption Analysis}

All transient absorption data were background-subtracted to remove scattered light and thermally lensed fluorescence from the spectra, and then corrected for group delay dispersion (GDD, or "chirp") using Surface Xplorer Pro 4 (Ultrafast Systems, LLC). Kinetic traces were fit in a laboratory-written MATLAB program. The program solves the differential equations of the specified kinetic model, then convolutes them with a Gaussian instrument response function before employing a least-squares fitting to iteratively find the parameters which result in matches to the same functions for all selected wavelengths. Once these parameters are established, they are fed into the model solutions to yield the populations of each state in model. Finally, the total raw data matrix is deconvoluted with these populations as functions of time to produce the spectra associated with each species.

We used the following first-order kinetic model with rate matrices $K$ : 


$$
K=\left(\begin{array}{ccrc}
-k_{1} & 0 & 0 & 0 \\
k_{1} & -k_{2} & 0 & 0 \\
0 & k_{2} & -k_{3} & 0 \\
0 & 0 & k_{3} & 0
\end{array}\right)
$$

where $\mathrm{k}_{1}$ represent the structural relaxation rate for $\mathbf{E x B o x}{ }^{\cdot 3+} . \mathrm{k}_{2}$ and $\mathrm{k}_{3}$ are the charge transfer rates from $\mathbf{E x B o x}^{\cdot 3+}$ to the intermediate state and from the intermediate state to NDI, respectively.
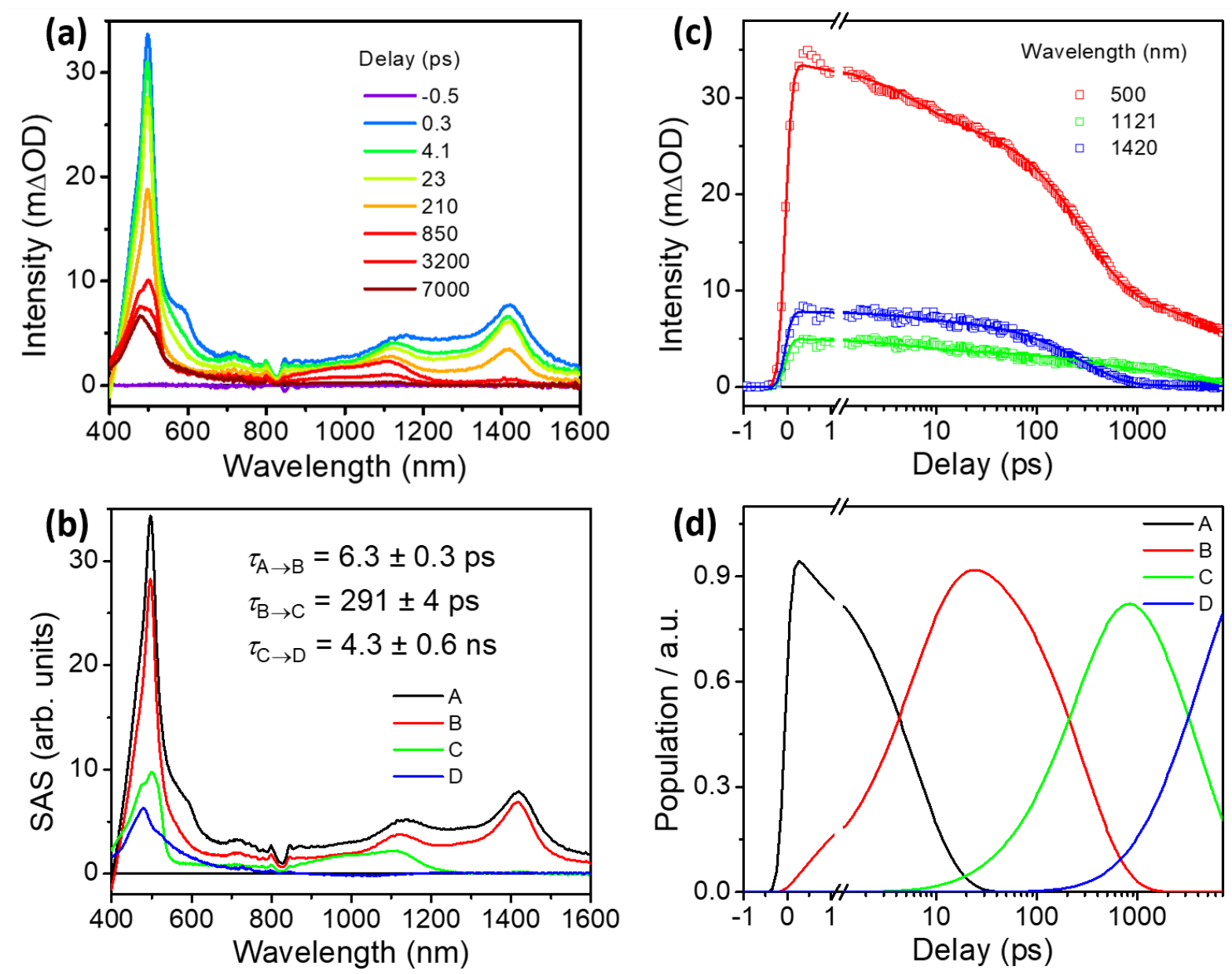

Figure S18. (a) fsTA Spectra and (b) species-associated spectra (SAS) and (c) multiple-wavelength fits and (d) populations of kinetic states of ExCat ${ }^{4+}$ in MeCN excited at $330 \mathrm{~nm}$. (A: nascent $\mathbf{E x B o x}^{\cdot 3+}$, B: relaxed ExBox ${ }^{\cdot 3+}$, C: intermediate charge transfer state, $\mathrm{D}: \mathrm{NDI}^{\bullet-}$ )

Femtosecond transient absorption is employed to further investigate the dynamics of ExCat ${ }^{4+}$ in $\mathrm{MeCN}$ upon photoexcitation at 330 nm, which is predominantly resonant with the absorption of $\mathbf{E x B o x}^{4+}$. The 
formation of reduced $\mathbf{E x B o x}^{4+}$ (state A in Figure S 18a) is observed within our instrument response timescale (about 0.3 ps), as evidenced by the transient features of $\mathbf{E x B o x}^{\bullet 3^{+}}$around 500, 1130 and $1420 \mathrm{~nm} .{ }^{4,5}$ This observation is highly consistent with the fluorescence quantum yield measurement of less than $0.1 \%$ in $\mathrm{MeCN}$ excited at $330 \mathrm{~nm}$, indicating the $\mathrm{S}_{1}$ state of $\mathbf{E x B o x}^{4+}$ is largely quenched by photo-induced charge transfer process. The nascent $\mathbf{E x B o x}{ }^{\bullet+}$ state undergoes a rapid structural relaxation with a timescale of 6.3 ps, and then it evolves to state $\mathrm{C}$, which is tentatively assigned to an intermediate charge transfer state. The final state $D$ is ascribed to the reduced NDI state with a main absorption band around $478 \mathrm{~nm}$, which matches with the UV-Vis-NIR spectrum of NDIOH $^{-}$in Figure 3b. We note that the sequential charge transfer dynamics from $\operatorname{ExBox}^{\bullet 3+}$ to NDI is in good agreement with the CV result of $\mathbf{E x C a t}^{4+}$ in Figure 6b, as the NDI moiety is more readily to be reduced compared to $\mathbf{E x B o x}{ }^{4+}$.

\section{UV-Stimulated Reduction}

a)

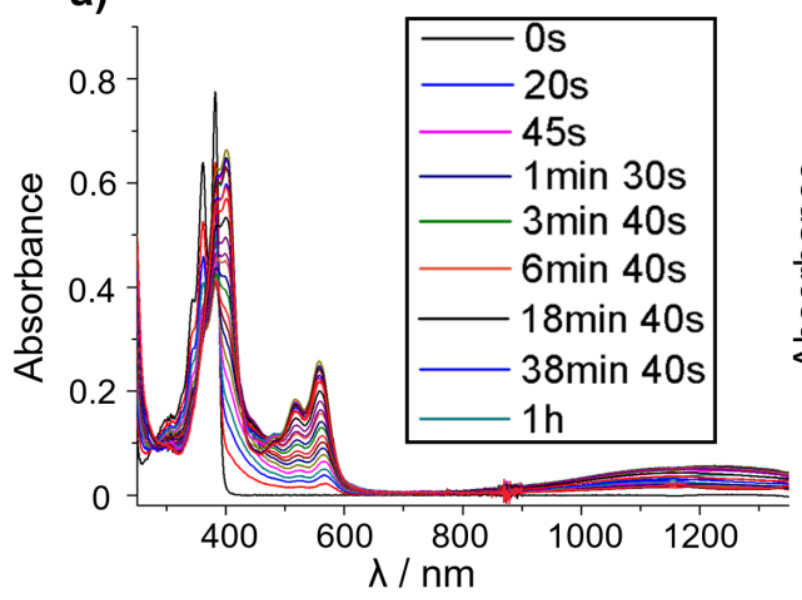

b)

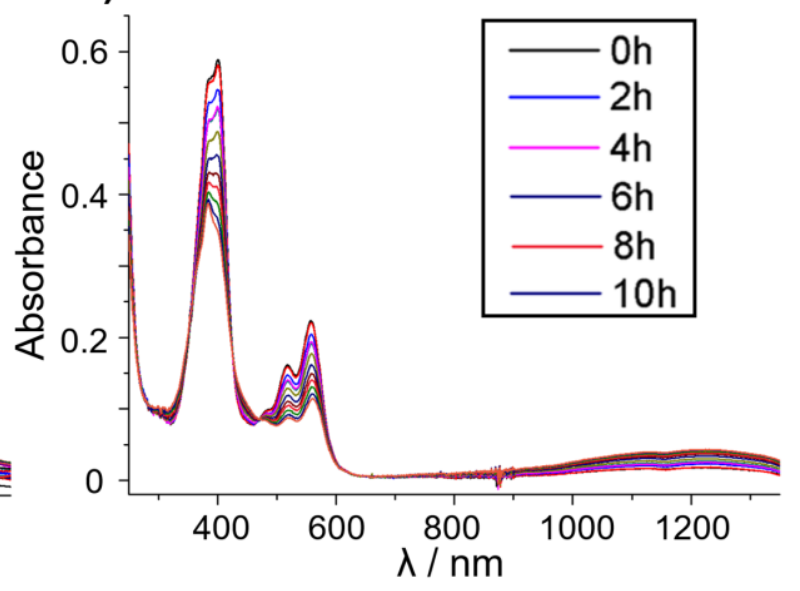

Figure S19. UV-Vis-NIR Absorption $\left(0.20 \mathrm{mM}\right.$, deaerated $\left.\mathrm{H}_{2} \mathrm{O}, 298 \mathrm{~K}\right)$ spectra of $\mathrm{NDIOH}, \mathrm{a})$ when the sample underwent UV light irradiation $\left(\lambda_{\mathrm{Ex}}=365 \mathrm{~nm}\right)$ for different amount of time, and b) the photo-reduced sample was exposed to air for different amount of time 

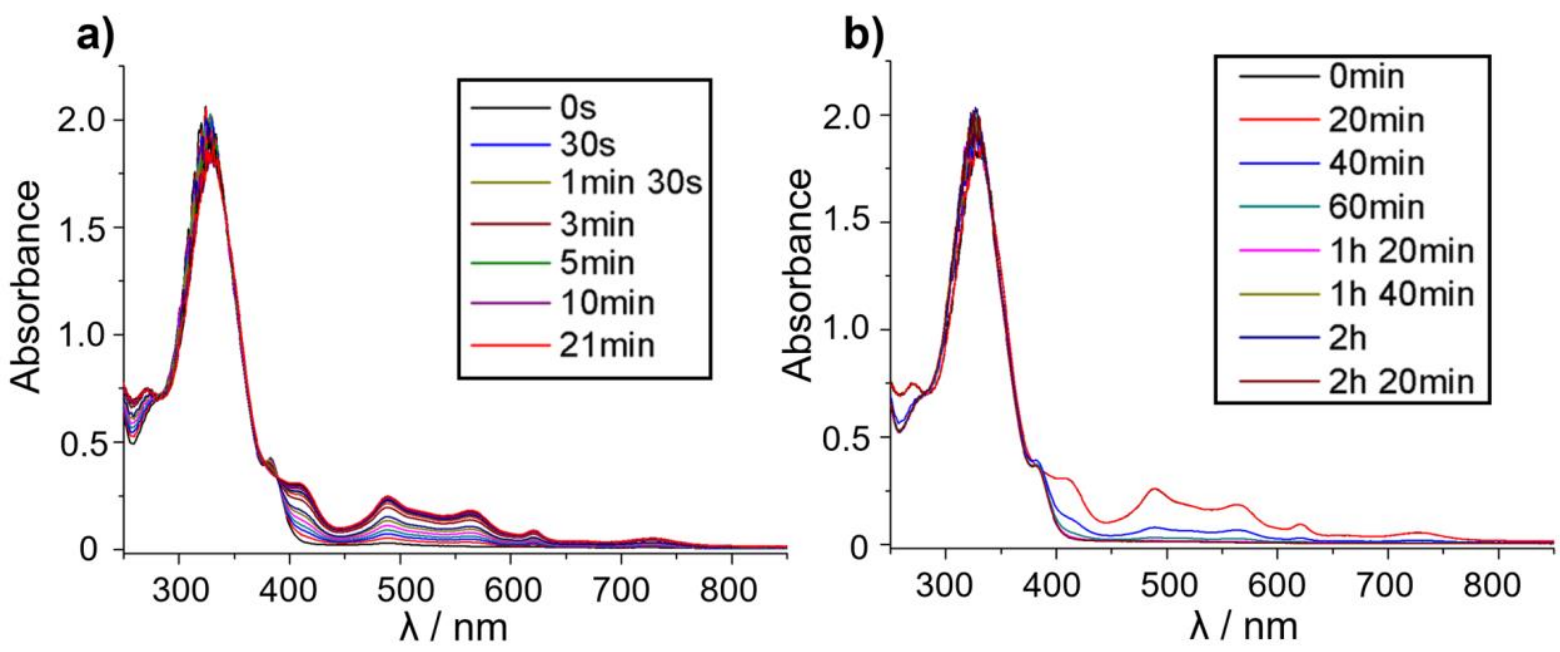

Figure S20. UV-Vis-NIR Absorption $\left(0.30 \mathrm{mM}\right.$, deaerated $\left.\mathrm{H}_{2} \mathrm{O}, 298 \mathrm{~K}\right)$ spectra of $\mathrm{NDIOH} \subset \mathrm{ExBox}^{4+}$, a) when the sample underwent UV light irradiation $\left(\lambda_{\mathrm{Ex}}=365 \mathrm{~nm}\right)$ for different amount of time, and b) the photo-reduced sample was exposed to air for different amount of time

a)

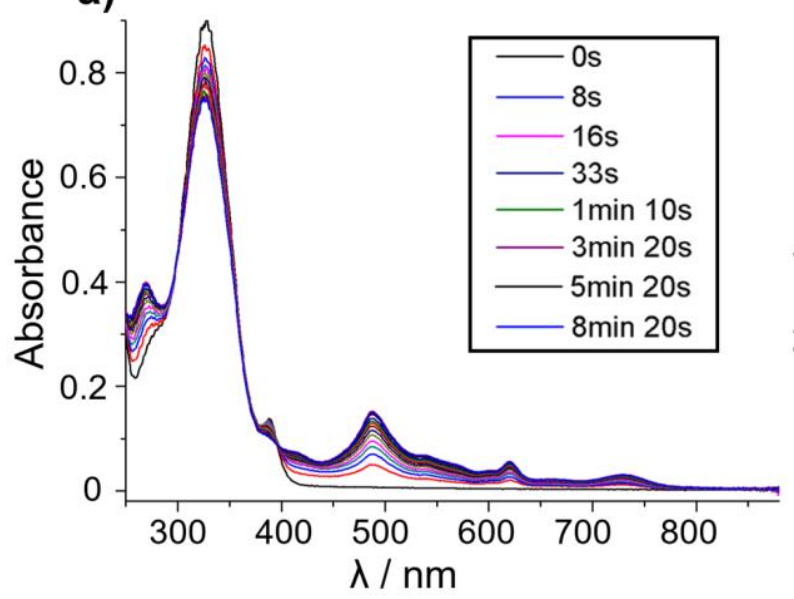

b)

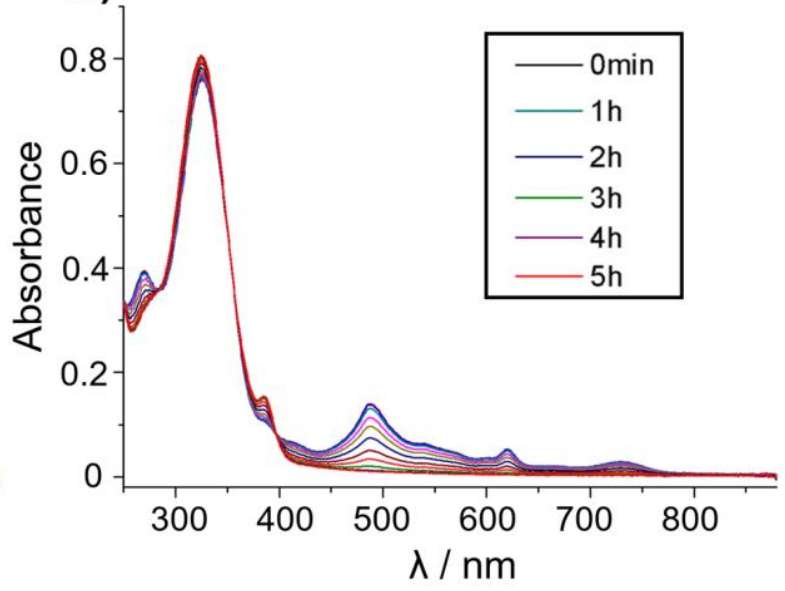

Figure S21. UV-Vis-NIR Absorption $\left(0.15 \mathrm{mM}\right.$, deaerated $\left.\mathrm{H}_{2} \mathrm{O}, 298 \mathrm{~K}\right)$ spectra of ExCat $^{4+}$, a) when the sample underwent UV light irradiation $\left(\lambda_{E x}=365 \mathrm{~nm}\right)$ for different amount of time, and b) the photo-reduced sample was exposed to air for different amount of time 

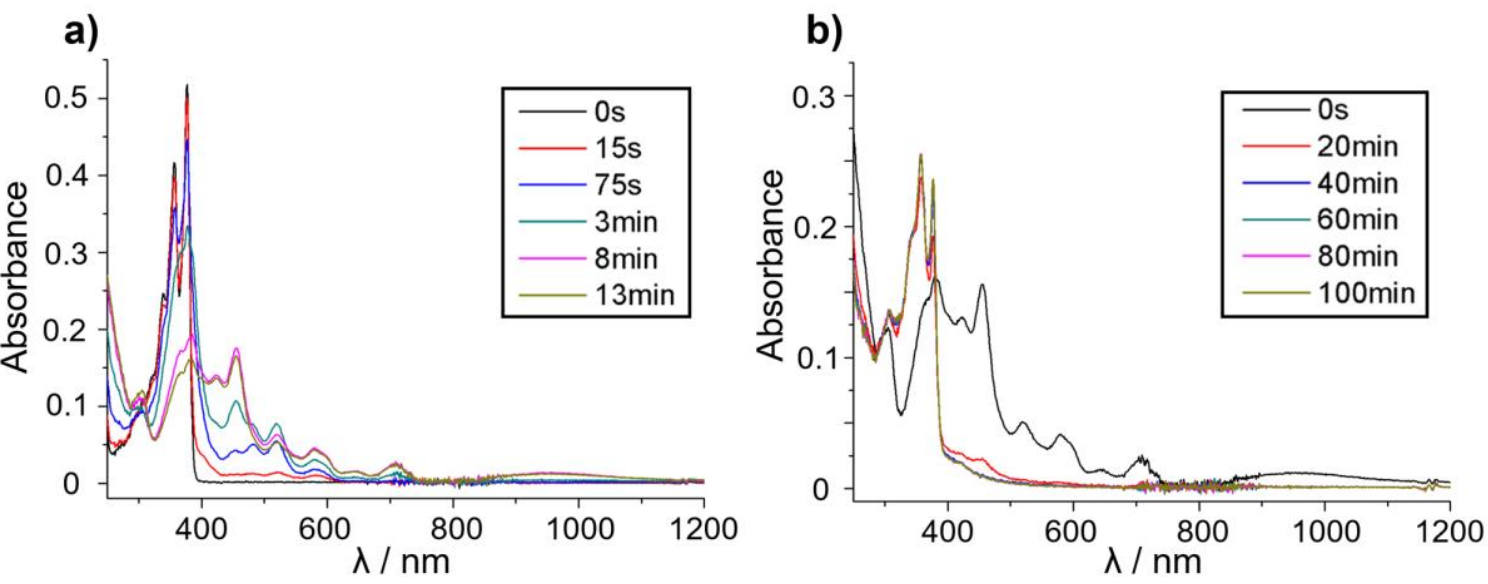

Figure S22. UV-Vis-NIR Absorption (0.12 mM, MeCN, $298 \mathrm{~K})$ spectra of NDIOH a) when the sample underwent UV light irradiation $\left(\lambda_{E x}=365 \mathrm{~nm}\right)$ for different amount of time, and b) the photo-reduced sample was exposed to air for different amount of time

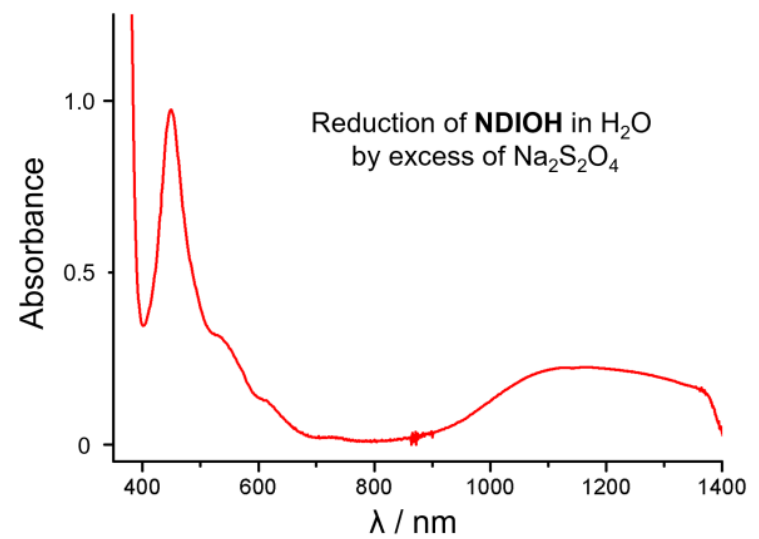

Figure S23. UV-Vis-NIR Absorption spectrum of NDIOH $\left(0.3 \mathrm{mM}, \mathrm{H}_{2} \mathrm{O}\right)$ after adding excess of $\mathrm{Na}_{2} \mathrm{~S}_{2} \mathrm{O}_{4}$, indicating the formation of $\mathrm{NDIOH}^{--}$dimer or pimers

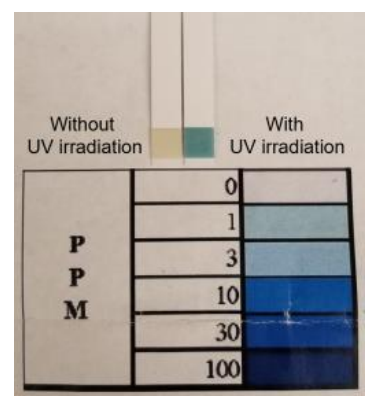

Figure S24. Peroxide test of the NDIOH solution $(0.1 \mathrm{mM})$ in $\mathrm{H}_{2} \mathrm{O}$ with and without UV irradiation ( $\lambda_{\mathrm{Ex}}=365 \mathrm{~nm}, 30 \mathrm{~min}$ ). The results showed irradiation of NDIOH solution under UV light led to the production of peroxide $(3-10 \mathrm{ppm})$. The peroxide concentration is measured semi-quantitatively by using EM Quant Peroxide Test Strips 


\section{X-ray Crystallography}

\section{1) NDIOHCExBox ${ }^{4+}$}

1.1) Methods

Solid NDIOH (1.0 mg, $1.6 \mu \mathrm{mol})$ was added to a solution of ExBox॰4PF6 in MeCN (2.0 mM, $0.75 \mathrm{~mL}$ ). After dissolving, the mixture was passed through a $0.45 \mu \mathrm{m}$ filter and split equally into three $1 \mathrm{~mL}$ tubes. The tubes were placed together in one $20 \mathrm{~mL}$ vial containing $i \operatorname{Pr}_{2} \mathrm{O}(\sim 3$ $\mathrm{mL}$ ) and the vial was capped. Slow vapor diffusion of $i \operatorname{Pr}_{2} \mathrm{O}$ into the solution of NDIOH and ExBox${ }^{\circ} 4 \mathrm{PF}_{6}$ in $\mathrm{MeCN}$ at $4{ }^{\circ} \mathrm{C}$ over the period of $14 \mathrm{~d}$ yielded yellow single crystals of NDIOH $\subset \mathbf{E x B o x}^{4+}$. X-Ray crystallographic data was collected on an Oxford Xcalibur Gemini Ultra diffractometer. The crystal was kept at $182 \mathrm{~K}$ during data collection. The structure was solved using Olex2 software ${ }^{6}$ with the ShelXS ${ }^{7}$ structure solution program by Direct Method and refined with the ShelXL ${ }^{8}$ refinement package through Least Squares minimization.

1.2) Crystal Data

$\mathrm{C}_{17} \mathrm{H}_{21} \mathrm{~N}_{2} \mathrm{O}_{6} \bullet\left(\mathrm{C}_{24} \mathrm{H}_{20} \mathrm{~N}_{2}\right)_{2} \bullet\left(\mathrm{C}_{2} \mathrm{H}_{3} \mathrm{~N}\right)_{3} \bullet\left(\mathrm{PF}_{6}\right)_{4}, M=1725.24$, triclinic, space group $P \overline{1}, a=$ 11.3842(6) $, b=18.1455(10), c=20.4946(11), \alpha=112.760(5), \beta=91.764(4), \gamma=102.586(5)$, $V=3778.9(4) \AA^{3}, Z=2, T=181.8 \mathrm{~K}, \mu(\mathrm{MoK} \alpha)=0.217 \mathrm{~mm}^{-1}$, Dcalc $=1.516 \mathrm{~g} / \mathrm{mm}^{3}, 28536$ reflections measured $\left(6.06^{\circ} \leq 2 \Theta \leq 50.7^{\circ}\right), 13784$ unique $\left(R_{\text {int }}=0.0559, R_{\text {sigma }}=0.0929\right)$ which were used in all calculations. The final $R_{l}$ was $0.1217(I>=2 \sigma(I))$ and $w R_{2}$ was 0.3929 (all data). CCDC number: 1874623

1.3) Solid-State (-Super) structures

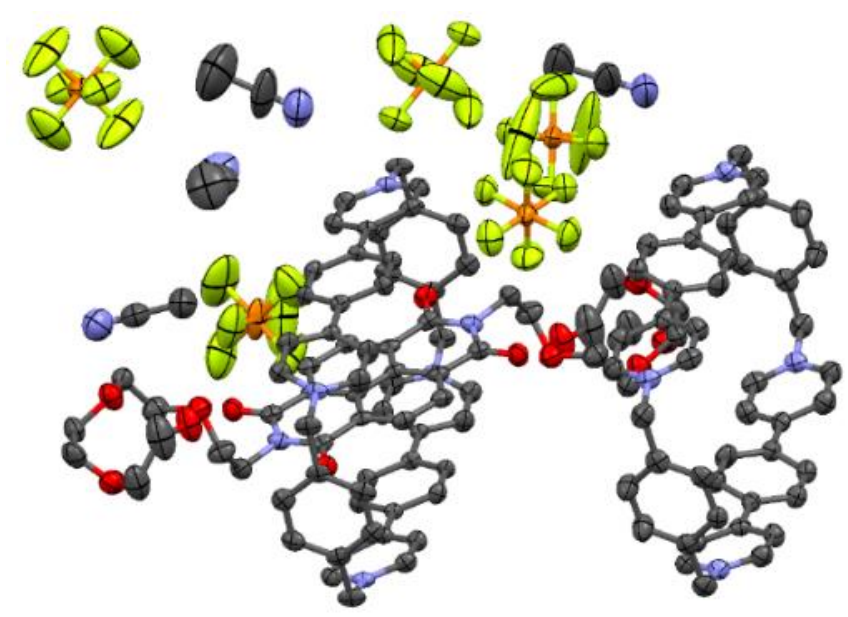

Figure S25. Thermal ellipsoids (50\% probability) plot of $\mathrm{NDIOH} \subset$ ExBox ${ }^{4+}$. C, gray, $\mathrm{N}$, light blue, $\mathrm{F}$, yellow, $\mathrm{P}$, orange 

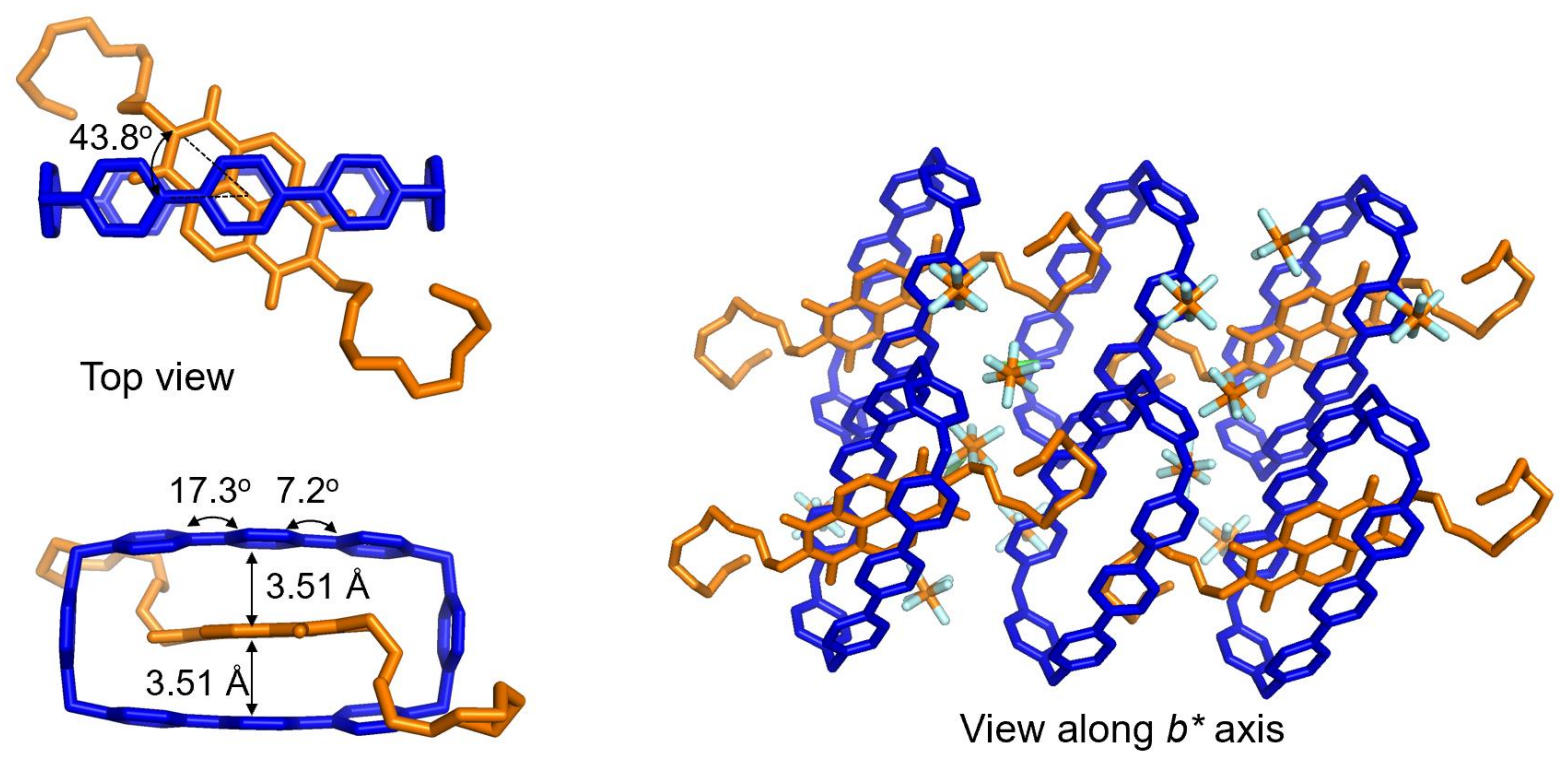

Side view

Figure S26. Different crystallographic views of NDIOHCExBox ${ }^{4+}$. ExBox ${ }^{4+}$ is shown in blue color, and NDIOH is shown in orange color

\section{2) $\mathrm{NDIOH}^{-} \subset \mathrm{ExBox}{ }^{4+}$}

\section{1) Methods}

The crystals of NDIOH $^{--} \boldsymbol{C E x B o x}{ }^{4+}$ were grown in an $\mathrm{N}_{2}$ glovebox at 298 K. NDIOH (1.24 $\mathrm{mg}, 2.0 \mu \mathrm{mol})$ was dissolved in $\mathrm{MeCN}(1.00 \mathrm{~mL})$ and $290 \mu \mathrm{L}$ of $\mathrm{CoCp}_{2}$ in $\mathrm{MeCN}(6.9 \mathrm{mM})$ was added. The color of the reation mixture changed from colorless to dark orange in 5 min, indicating that NDIOH was fully reduced as single radical state. Then, $\mathbf{E x B o x} 4 \mathrm{PF}_{6}(2.51 \mathrm{mg}$, $2.0 \mu \mathrm{mol}$ ) was added to the above solution. After dissolving, the mixture was passed through a $0.45 \mu \mathrm{m}$ filter and split equally into three $1 \mathrm{~mL}$ tubes. The tubes were placed together in one $20 \mathrm{~mL}$ vial containing $i \operatorname{Pr}_{2} \mathrm{O}(\sim 3 \mathrm{~mL})$ and the vial was capped. Slow vapor diffusion of $i \operatorname{Pr}_{2} \mathrm{O}$ into the solution of $\mathbf{N D I O H}^{--}$and $\mathbf{E x B o x} \cdot 4 \mathrm{PF}_{6}$ in $\mathrm{MeCN}$ at room temperature over the period of $14 \mathrm{~d}$ yielded black needles crystals of $\mathbf{N D I O H}^{{ }^{-}} \subset \mathbf{E x B o x}{ }^{4+}$. A suitable crystal was selected and the crystal was mounted on a MITIGEN holder in Paratone oil on a Bruker Kappa APEX CCD area detector diffractometer. The crystal was kept at $100.01 \mathrm{~K}$ during data collection. The structure was solved using Olex 2 software ${ }^{6}$ with the $\mathrm{XT}^{9}$ structure solution program by Intrinsic Phasing and refined with the $\mathrm{XL}^{7}$ refinement package using Least Squares minimization. 


\section{2) Crystal Data}

$\left(\mathrm{C}_{24} \mathrm{H}_{20} \mathrm{~N}_{2}\right)_{2} \bullet\left(\mathrm{C}_{15} \mathrm{H}_{19} \mathrm{NO}_{6}\right)_{0.8} \bullet\left(\mathrm{C}_{2} \mathrm{H}_{3} \mathrm{~N}\right)_{2.8} \bullet\left(\mathrm{PF}_{6}\right)_{3.2}, M=1499.14$, triclinic, space group $P \overline{1}$ (no.2), $a=10.9442(7), b=16.0723(12), c=19.1059(13), \alpha=94.246(4), \beta=90.646(4), \gamma=$ 92.596(4), $V=3347.7(4) \AA^{3}, Z=2, T=100.01 \mathrm{~K}, \mu(\mathrm{CuK} \alpha)=1.834 \mathrm{~mm}^{-1}$, Dcalc $=$ $1.487 \mathrm{~g} / \mathrm{mm}^{3}, 23296$ reflections measured $(5.52 \leq 2 \Theta \leq 128.102), 10819$ unique $\left(R_{\text {int }}=0.0307\right.$, $\left.R_{\text {sigma }}=0.0375\right)$ which were used in all calculations. The final $R_{l}$ was $0.0829(I>2 \sigma(I))$ and $w R_{2}$ was 0.2433 (all data). CCDC number: 1894476

The structure has a $20 \%$ disorder with ${\mathrm{a} \mathrm{PF}_{6}}^{-}$. Distance restraints were imposed on the disordered $\mathrm{PF}_{6}{ }^{-}$anions along with the disorder carbon and oxygen atoms. Rigid bond restraints were imposed on the displacement parameters as well as restraints on similar amplitudes separated by less than $1.7 \AA$ were also imposed on those atoms.

2.3) Solid-State (-Super) structures

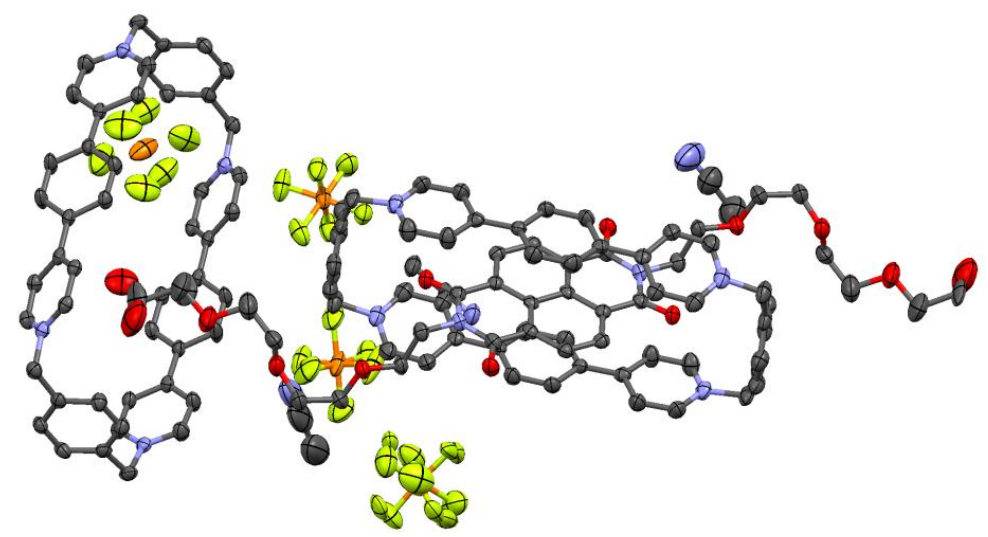

Figure S27. Thermal ellipsoids (50\% probability) plot of $\mathrm{NDIOH}^{--} \subset \mathrm{ExBOx}^{4+}$. C, gray, $\mathrm{N}$, light blue, $\mathrm{F}$, yellow, $\mathrm{P}$, orange

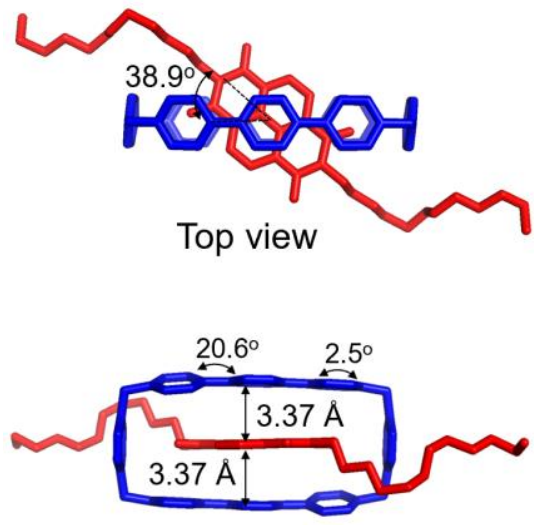

Side view

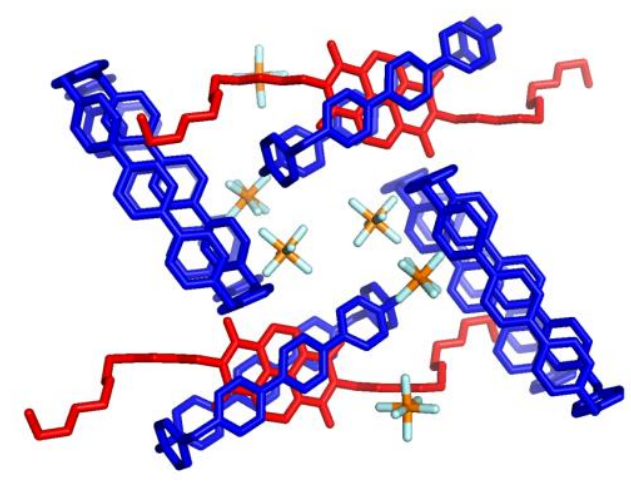

View along a axis

Figure S28. Different crystallographic views of $\mathrm{NDIOH}^{--} \subset \mathrm{ExBox}^{4+}$. ExBox ${ }^{4+}$ is shown in blue color, and $\mathrm{NDIOH}^{-}$is shown in red color 


\section{3) $\mathrm{ExCat}^{4+}$}

3.1) Methods

Single crystals of ExCat ${ }^{4+}$ were grown at room temperature by slow vapor diffusion of $i \operatorname{Pr}_{2} \mathrm{O}$ into a solution of ExCat ${ }^{4} \mathrm{PF}_{6}$ in $\mathrm{Me}_{2} \mathrm{CO}(2.0 \mathrm{mM})$. A suitable crystal was selected and the crystal was mounted on a glass fibre in Paratone oil on a Bruker Kappa APEX CCD area detector diffractometer. The crystal was kept at $99.99 \mathrm{~K}$ during data collection. The structure was solved using Olex2 software ${ }^{6}$ with the ShelXT ${ }^{9}$ structure solution program using Intrinsic Phasing and refined with the $\mathrm{XL}^{7}$ refinement package using Least Squares minimization.

3.2) Crystal data $\left(\mathrm{C}_{48} \mathrm{H}_{40} \mathrm{~N}_{4}\right) \bullet\left(\mathrm{C}_{36} \mathrm{H}_{40} \mathrm{~N}_{2} \mathrm{O}_{12}\right) \bullet\left(\mathrm{PF}_{6}\right)_{4}, M=1945.42$, monoclinic, space group $C 2 / c$ (no. 15), $a=$ 44.908(2) $, b=17.6979(8), c=27.6580(12), \beta=113.317(2), V=20186.8(16) \AA^{3}, Z=8, T=$ $99.99 \mathrm{~K}, \mu(\mathrm{CuK} \alpha)=1.576 \mathrm{~mm}^{-1}$, Dcalc $=1.280 \mathrm{~g} / \mathrm{mm}^{3}, 79617$ reflections measured $(4.286 \leq$ $2 \Theta \leq 125.062), 16052$ unique $\left(R_{\text {int }}=0.0674, R_{\text {sigma }}=0.0512\right)$ which were used in all calculations. The final $R_{1}$ was $0.0810(I>2 \sigma(I))$ and $w R_{2}$ was 0.2575 (all data). CCDC number: 1894477

Distant restraints were imposed on the disordered $\mathrm{PF}_{6}{ }^{-}$and carbon chains. Rigid bond restraints were imposed on the displacement parameters as well as restraints on similar amplitudes separated by less than $1.7 \AA$ on the disordered carbon atoms. The solvent masking procedure as implemented in Olex2 was used to remove the electronic contribution of solvent molecules from the refinement. As the exact solvent content is not known, only the atoms used in the refinement model are reported in the formula here. Total solvent accessible volume $/$ cell $=$ $4365.2 \AA 3$ [21.6\%] Total electron count / cell = 1238.6.

3.3) Solid-State (-Super) structures

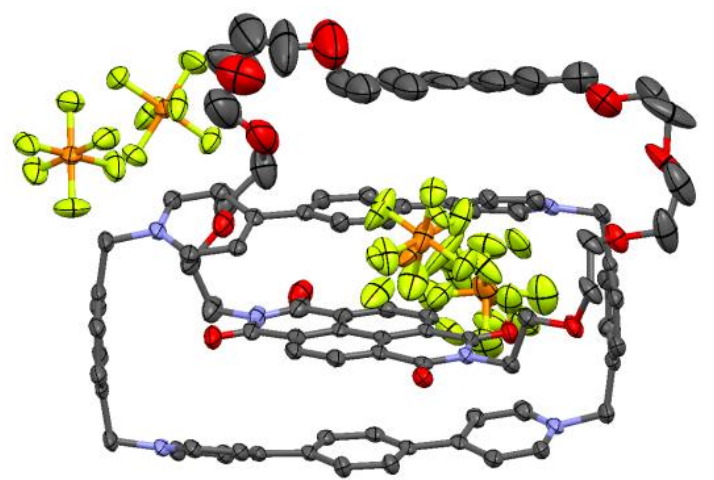

Figure S29. Thermal ellipsoids (50\% probability) plot of ExCat ${ }^{4+}$. C, gray, N, light blue, $F$, yellow, $P$, orange 


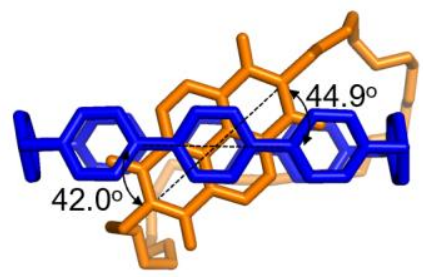

Top view

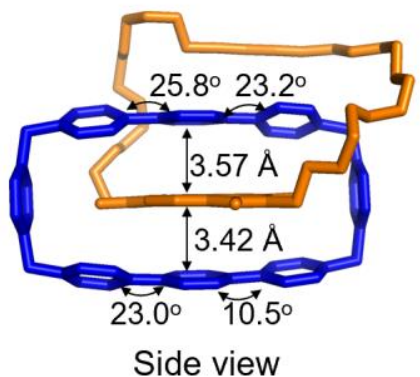

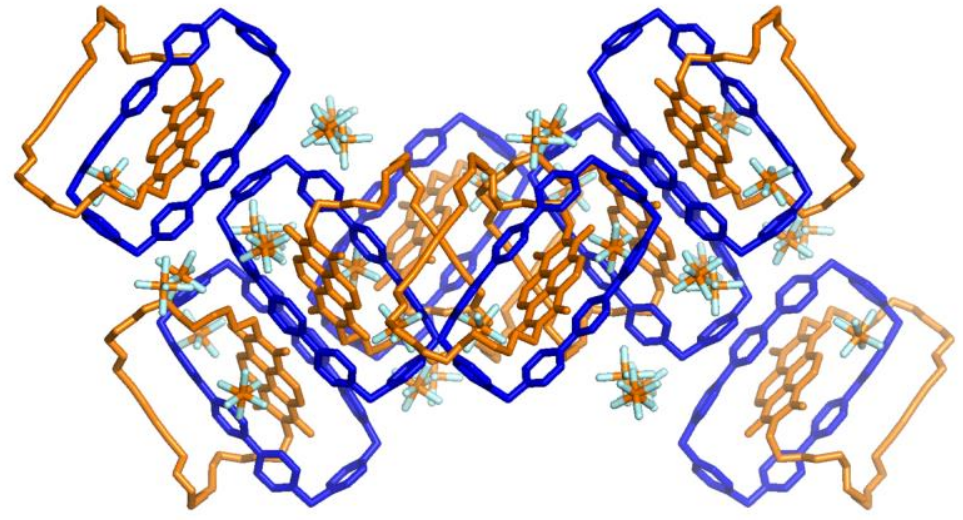

View along $c^{*}$ axis

Figure S30. Different crystallographic views of ExCat ${ }^{4+}$. The part of ExBox ${ }^{4+}$ is shown in blue color, and the part of NDIOH is shown in red color

4) $\mathrm{ExCat}^{(4+)(\cdot)}$

\section{1) Methods}

The crystals of ExCat ${ }^{(4+)(\bullet-)}$ were grown in an $\mathrm{N}_{2}$ glovebox at $298 \mathrm{~K}$. ExCat•4PF 6 (1.95 mg, $1.0 \mu \mathrm{mol})$ was dissolved in $\mathrm{Me}_{2} \mathrm{CO}(1.00 \mathrm{~mL})$ and $146 \mu \mathrm{L}$ of $\mathrm{CoCp}_{2}$ in $\mathrm{MeCN}(6.9 \mathrm{mM})$ was added. The color of the reation mixture changed from colorless to dark orange in $5 \mathrm{~min}$, which indicated that ExCat•4PF 6 was fully reduced as $\mathbf{E x C a t}^{(4+)(\bullet-)} \cdot 3 \mathrm{PF}_{6}$. The mixture was passed through a $0.45 \mu \mathrm{m}$ filter and split equally into three $1 \mathrm{~mL}$ tubes. The tubes were placed together in one $20 \mathrm{~mL}$ vial containing $i \operatorname{Pr}_{2} \mathrm{O}(\sim 3 \mathrm{~mL})$ and the vial was capped. Slow vapor diffusion of $i \mathrm{Pr}_{2} \mathrm{O}$ into the solution of $\mathbf{E x C a t}^{(4+)(-) \cdot} \cdot 3 \mathrm{PF}_{6}$ in $\mathrm{Me}_{2} \mathrm{CO}$ at room temperature over the period of $3 \mathrm{~d}$ yielded black needles crystals of $\mathbf{E x C a t}^{(4+)(\cdot)}$. A suitable crystal was selected and the crystal was mounted on a MITIGEN holder on a Kappa Apex 2 diffractometer. The crystal was kept at $100.0 \mathrm{~K}$ during data collection. The structure was solved using Olex 2 software $^{6}$ with the ShelXT ${ }^{9}$ structure solution program by Intrinsic Phasing and refined with the $\mathrm{XL}^{7}$ refinement package using Least Squares minimization.

4.2) Crystal data

$\left(\mathrm{C}_{48} \mathrm{H}_{40} \mathrm{~N}_{4}\right) \bullet\left(\mathrm{C}_{36} \mathrm{H}_{40} \mathrm{~N}_{2} \mathrm{O}_{12}\right) \bullet\left(\mathrm{C}_{2} \mathrm{H}_{3} \mathrm{~N}\right) \bullet\left(\mathrm{PF}_{6}\right)_{3}, M=1841.50$, monoclinic, space group $P 21 / c$ (no.

14), $a=17.5470(13), b=27.825(3), c=18.3914(14), \beta=101.895(6), V=8786.6(12) \AA^{3}$, $Z=4, T=100.0 \mathrm{~K}, \mu(\mathrm{CuK} \alpha)=1.514 \mathrm{~mm}^{-1}$, Dcalc $=1.392 \mathrm{~g} / \mathrm{mm}^{3}, 20915$ reflections measured 
$(5.848 \leq 2 \Theta \leq 108.594), 10467$ unique $\left(R_{\text {int }}=0.0765, R_{\text {sigma }}=0.1277\right)$ which were used in all calculations. The final $R_{1}$ was $0.1616(I>2 \sigma(I))$ and $w R_{2}$ was 0.4184 (all data). CCDC number: 1894478

The enhanced rigid-bond restraint (SHELX keyword RIGU) was applied globally. Distance restraints were imposed on the disordered Carbon atoms. The solvent masking procedure as implemented in Olex2 was used to remove the electronic contribution of solvent molecules from the refinement. As the exact solvent content is not known, only the atoms used in the refinement model are reported in the formula here. Total solvent accessible volume / cell = $917.4 \AA^{3}[10.4 \%]$ Total electron count $/$ cell $=258.5$.

4.3) Solid-State (-Super) structures

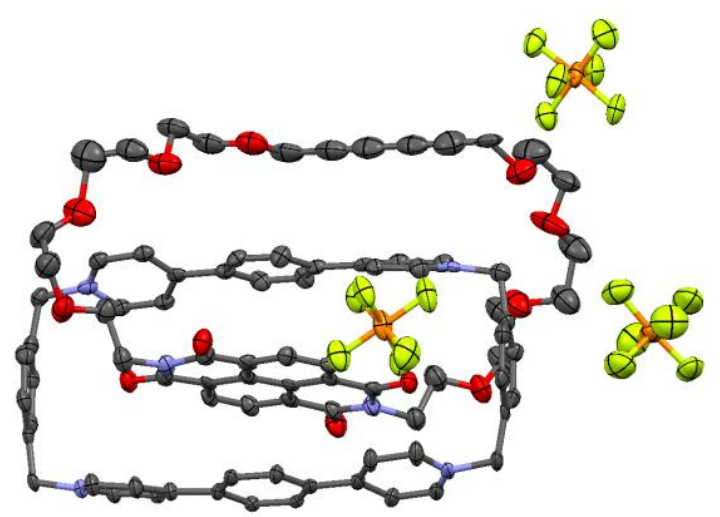

Figure S31. Thermal ellipsoids (50\% probability) plot of ExCat $\left.{ }^{(4+)}\right)^{(-)}$. C, gray, N, light blue, $F$, yellow, $P$, orange

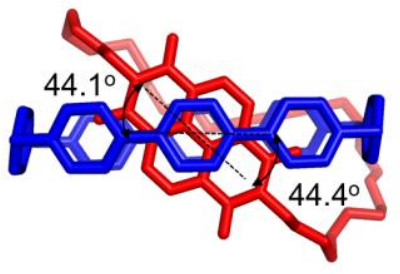

Top view

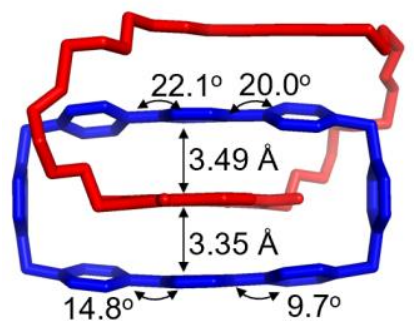

Side view

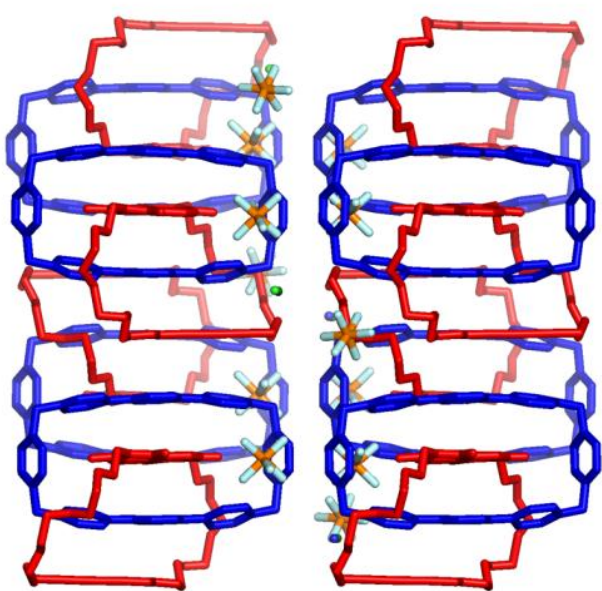

View along $a$ axis

Figure S32. Different crystallographic views of ExCat ${ }^{(4+)(-)}$. The part of ExBox ${ }^{4+}$ is shown in blue color, and the part of $\mathrm{NDIOH}^{--}$is shown in red color 


\section{DFT Calculations}

DFT Calculations were performed to evaluate the free energy change $(\Delta G)$, which is defined as the free energy difference between the complex and the corresponding unbound guest and host, for the formation of $\mathbf{N D I} \subset \mathbf{E x B o x}{ }^{4+}$ and $\mathbf{N D I}^{--} \subset \mathbf{E x B o x}{ }^{4+}$. The $\Delta G$ values for the formation of NDI $\subset \mathbf{E x B o x}{ }^{4+}$ and $\mathbf{N D I}^{-} \subset \mathbf{E x B o x}{ }^{4+}$ were calculated to be -2.6 and $-11.5 \mathrm{kcal} /$ mol, respectively.

The free energy change $(\Delta G)$ value of the reaction $* \mathbf{N D I O H}^{--}+\mathbf{N D I O H}^{--} \rightarrow \mathrm{NDIOH}^{2-}+$ NDIOH was calculated to be $-31.4 \mathrm{kcal} / \mathrm{mol}$.

All calculations were performed with Gaussian $09 .{ }^{10}$ Geometry optimization of all the minima involved was carried out at the M06-2X level of theory ${ }^{11,12}$ with the 6-31G(d) basis set. ${ }^{13}$ The vibrational frequencies were computed at the same level to check whether each optimized structure is an energy minimum and to evaluate its zero-point vibrational energy (ZPVE) and thermal corrections at $298 \mathrm{~K}$. The single-point energies and solvent effects in acetonitrile were computed at the M06-2X level of theory with the $6-311++\mathrm{G}(\mathrm{d}, \mathrm{p})$ basis set, ${ }^{13}$ based on the gasphase optimized structures. The photoexcited state of NDI radical anion $\left({ }^{*} \mathrm{NDI}^{\bullet-}\right)$ was optimized and calculated by time-dependent DFT. Solvation energies were evaluated by a selfconsistent reaction field (SCRF) using the SMD model. ${ }^{14}$ The 3D diagrams of molecules were generated using CYLView. ${ }^{15}$

a)

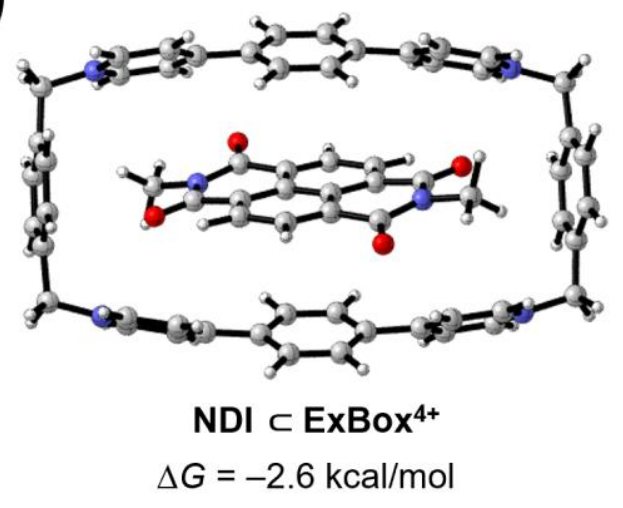

b)

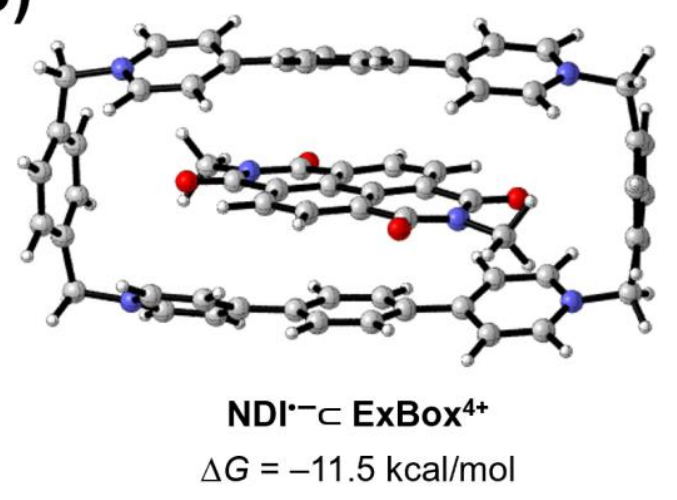

Figure S33. DFT-Optimized structures of a) NDICExBox ${ }^{4+}$ and b) $\mathrm{NDI}^{\cdot-} \subset \mathbf{E x B o x}{ }^{4+}$. The free energy changes $(\Delta G)$ for the formation of NDICExBox ${ }^{4+}$ and $\mathrm{NDI}^{\cdot-} \subset \mathrm{ExBox}^{4+}$ complexes are calculated to be -2.6 and $-11.5 \mathrm{kcal} / \mathrm{mol}$, respectively. 
The singly occupied molecular orbital (SOMO) and spin density distribution for the complex were calculated by using the Multiwfn software ${ }^{16}$ based on the DFT-optimized structure at the UM06-2x/6-311++G(d,p) level of theory, and visualized by the Visual Molecular Dynamics (VMD) software. ${ }^{17}$
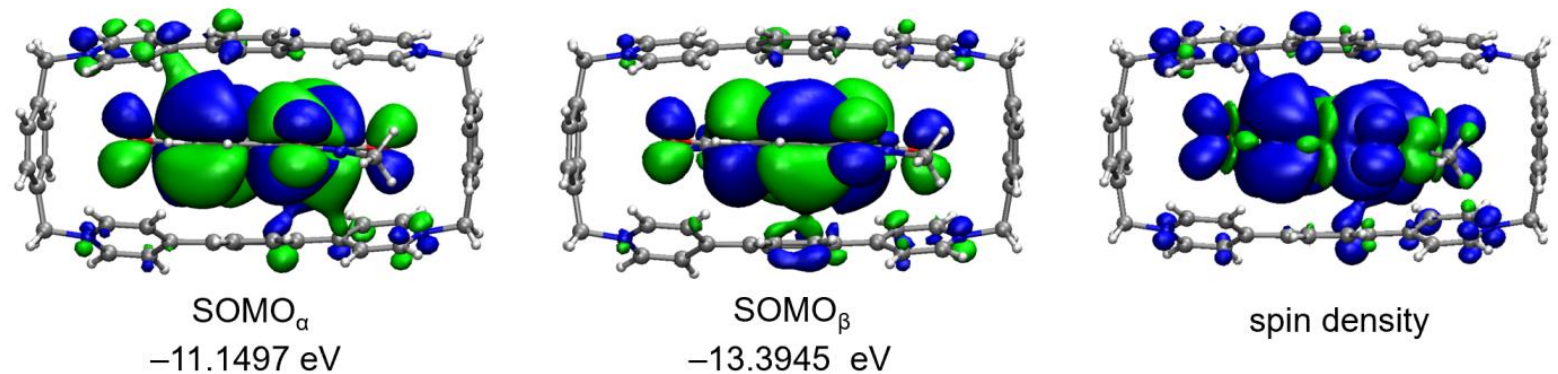

Figure S34. Calculated SOMOs and spin density distribution of $\mathrm{NDI}^{\circ-} \subset \mathrm{ExBOx}^{4+}$ (UM06-2x/6-311++G(d,p)).

The calculated spin density distribution supports our argument that the SOMO of the radical anion is still primarily localized on the $\mathrm{NDI}^{-}$. There is little electron delocalization of electron density from the guest to the macrocyclic host.

Table S1. Detailed computed energies (in Hartrees) of optimized structures at M062X/6-311++G(d,p)-SMD(acetonitrile)//M06-2X/6-31G(d)

\begin{tabular}{|c|c|c|c|c|c|}
\hline Structure & $\operatorname{ExBox}^{4+}$ & NDI & $\mathrm{NDI}^{\circ}$ & NDI $\subset \operatorname{ExBox}{ }^{4+}$ & $\mathrm{NDI}^{-} \subset \mathrm{ExBox}^{4+}$ \\
\hline $\begin{array}{l}\text { Electronic Energy } \\
\text { (EE) }\end{array}$ & -2071.32665 & -1026.131162 & -1026.267227 & -3097.493964 & -3097.646873 \\
\hline $\begin{array}{l}\text { Zero-point Energy } \\
\text { Correction }\end{array}$ & 0.775862 & 0.239422 & 0.237072 & 1.017852 & 1.016286 \\
\hline $\begin{array}{c}\text { Thermal Correction } \\
\text { to Energy }\end{array}$ & 0.815550 & 0.256251 & 0.253975 & 1.074818 & 1.072946 \\
\hline $\begin{array}{c}\text { Thermal Correction } \\
\text { to Enthalpy }\end{array}$ & 0.816494 & 0.257195 & 0.254919 & 1.075762 & 1.073890 \\
\hline $\begin{array}{c}\text { Thermal Correction } \\
\text { to Free Energy }\end{array}$ & 0.700987 & 0.195138 & 0.191668 & 0.928060 & 0.927361 \\
\hline $\begin{array}{c}\text { Imaginary } \\
\text { Frequency }\left(\mathrm{cm}^{-1}\right)\end{array}$ & - & - & - & - & - \\
\hline
\end{tabular}


Table S2. Detailed computed energies (in Hartrees) of optimized structures at M062X/6-311++G(d,p)-SMD(water)//M06-2X/6-31G(d)

\begin{tabular}{|c|c|c|c|c|}
\hline Structure & NDI & NDI $^{-}$ & NDI $^{-2}$ & $*^{-}$ \\
\hline $\begin{array}{c}\text { Electronic Energy } \\
\text { (EE) }\end{array}$ & -2071.32665 & -1026.131162 & -1026.267227 & -3097.493964 \\
\hline $\begin{array}{c}\text { Zero-point Energy } \\
\text { Correction }\end{array}$ & 0.775862 & 0.239422 & 0.237072 & 1.017852 \\
\hline $\begin{array}{c}\text { Thermal Correction } \\
\text { to Energy }\end{array}$ & 0.815550 & 0.256251 & 0.253975 & 1.074818 \\
\hline $\begin{array}{c}\text { Thermal Correction } \\
\text { to Enthalpy }\end{array}$ & 0.816494 & 0.257195 & 0.254919 & 1.075762 \\
\hline $\begin{array}{c}\text { Thermal Correction } \\
\text { to Free Energy }\end{array}$ & 0.700987 & 0.195138 & 0.191668 & 0.928060 \\
\hline $\begin{array}{c}\text { Imaginary } \\
\text { Frequency }\left(\mathrm{cm}{ }^{-1}\right)\end{array}$ & - & - & - & - \\
\hline
\end{tabular}

\section{References}

1. Barnes, J. C.; Juríček, M.; Vermeulen, N. A.; Dale, E. J.; Stoddart, J. F. Synthesis of Ex ${ }^{n}$ Box Cyclophanes. J. Org. Chem. 2013, 78, 11962-11969.

2. Goswami, L. N.; Houston, Z. H.; Sarma, S. J.; Jalisatgi, S. S. Efficient Synthesis of Diverse Heterobifunctionalized Clickable Oligo(ethylene glycol) Linkers: Potential Applications in Bioconjugation and Targeted Drug Delivery. Org. Biomol. Chem. 2013, 11, 1116-1126.

3. Hansen, J. G.; Feeder, N.; Hamilton, D. G.; Gunter, M. J.; Becher, J.; Sanders, J. K. Macrocyclization and Molecular Interlocking via Mitsunobu Alkylation: Highlighting the Role of $\mathrm{C}-\mathrm{H} \cdots \mathrm{O}$ Interactions in Templating. Org. Lett. 2000, 2, 449-452.

4. Young, R. M.; Dyar, S. M.; Barnes, J. C.; Juríček, M.; Stoddart, J. F.; Co, D. T.; Wasielewski, M. R., Ultrafast Conformational Dynamics of Electron Transfer in ExBox ${ }^{4+} \subset$ Perylene. J. Phy. Chem. A 2013, $117,12438-12448$.

5. Wu, Y. L.; Zhou, J. W.; Phelan, B. T.; Mauck, C. M.; Stoddart, J. F.; Young, R. M.; Wasielewski, M. R., Probing Distance Dependent Charge-Transfer Character in Excimers of Extended Viologen 
Cyclophanes Using Femtosecond Vibrational Spectroscopy. J. Am. Chem. Soc. 2017, 139, 1426514276.

6. Dolomanov, O. V.; Bourhis, L. J.; Gildea, R. J.; Howard, J. A. K.; Puschmann, H. OLEX2: a Complete Structure Solution, Refinement and Analysis Program. J. Appl. Cryst. 2009, 42, 339-341.

7. Sheldrick, G.M. A Short History of SHELX. Acta Cryst. 2008, A64, 112-122.

8. Sheldrick, G.M. Crystal Structure Refinement with SHELXL. Acta Cryst. 2015, C71, 3-8.

9. Sheldrick, G.M. SHELXT - Integrated Space-Group and Crystal-Structure Determination. Acta Cryst. 2015, $A 71,3-8$.

10. Frisch, M. J.; Trucks, G. W.; Schlegel, H. B.; Scuseria, G. E.; Robb, M. A.; Cheeseman, J. R.; Scalmani, G.; Barone, V.; Mennucci, B.; Petersson, G. A.; Nakatsuji, H.; Caricato, M.; Li, X.; Hratchian, H. P.; Izmaylov, A. F.; Bloino, J.; Zheng, G.; Sonnenberg, J. L.; Hada, M.; Ehara, M.; Toyota, K.; Fukuda, R.; Hasegawa, J.; Ishida, M.; Nakajima, T.; Honda, Y.; Kitao, O.; Nakai, H.; Vreven, T.; Montgomery, J. A., Jr.; Peralta, J. E.; Ogliaro, F.; Bearpark, M.; Heyd, J. J.; Brothers, E.; Kudin, K. N.; Staroverov, V. N.; Kobayashi, R.; Normand, J.; Raghavachari, K.; Rendell, A.; Burant, J. C.; Iyengar, S. S.; Tomasi, J.; Cossi, M.; Rega, N.; Millam, J. M.; Klene, M.; Knox, J. E.; Cross, J. B.; Bakken, V.; Adamo, C.; Jaramillo, J.; Gomperts, R.; Stratmann, R. E.; Yazyev, O.; Austin, A. J.; Cammi, R.; Pomelli, C.; Ochterski, J. W.; Martin, R. L.; Morokuma, K.; Zakrzewski, V. G.; Voth, G. A.; Salvador, P.; Dannenberg, J. J.;Dapprich, S.;Daniels,A.D.; Farkas,O.; Foresman, J. B.; Ortiz, J. V.; Cioslowski, J.; Fox, D. J.; Gaussian 09, revision C.01; Gaussian Inc.: Wallingford, CT, 2010.

11. Zhao, Y.; Truhlar, D. G. Density Functionals with Broad Applicability in Chemistry. Acc. Chem. Res. 2008, 41, 157-167.

12. Zhao, Y.; Truhlar, D. G. The M06 Suite of Density Functionals for Main Group Thermochemistry, Thermochemical Kinetics, Noncovalent Interactions, Excited States, and Transition Elements: Two New Functionals and Systematic Testing of Four M06-class Functionals and 12 Other Functionals. Theor. Chem. Acc. 2008, 120, 215-241.

13. Hehre, W. J.; Radom, L.; Schleyer, P. v. R.; Pople, J. A. Ab Initio Molecular Orbital Theory; Wiley: New York, 1986. 
14. Marenich, A. V.; Cramer, C. J.; Truhlar, D. G. Universal Solvation Model Based on Solute Electron Density and on a Continuum Model of the Solvent Defined by the Bulk Dielectric Constant and Atomic Surface Tensions. J. Phys. Chem. B 2009, 113, 6378-6396.

15. Legault, C. Y. CYLView 2009, 1.0b, http://www.cylview.org.

16. Lu, T.; Chen, F., Multiwfn: A multifunctional wavefunction analyzer. J. Comput. Chem. 2012, 33, $580-592$.

17. Humphrey, W., Dalke, A. and Schulten, K., VMD - Visual Molecular Dynamics. J. Molec. Graphics 1996, 14.1, 33-38.

\section{Cartesian Coordinates for the Optimized Structures}

\section{$\operatorname{ExBox}^{4+}$}

N $5.565737003 .44019000-0.00055200$

N -5.56573900 $3.44018800-0.00055100$

C 4.832616003 .228448001 .11264600

H 5.346514002 .749198001 .93904700

C 3.499409003 .569496001 .15929700

H 2.939810003 .348381002 .06100400

C 2.872557004 .130293000 .03378800

C $3.681400004 .40531600-1.07822000$

H $3.283495004 .90066900-1.95732600$

C $5.017215004 .04993200-1.07041500$

H $5.674410004 .23658200-1.91312700$

C 1.404108004 .324397000 .01095000

C 0.694070004 .650824001 .17515200

H 1.223643004 .921842002 .08388400

C - 0.694072004 .650824001 .17515200

H - 1.223645004 .921841002 .08388400

C - 1.404111004 .324396000 .01095000

C - $0.694223004 .07184600-1.16907600$

H -1.22083800 $3.81376000-2.08276100$

C $0.694220004 .07184600-1.16907600$

H $1.220835003 .81376000-2.08276100$

C - 2.872559004 .130293000 .03378800

C -3.49941100 3.569496001 .15929800

H -2.93981200 3.348382002 .06100500

C - 4.832619003 .228448001 .11264700

H -5.34651700 2.74919900 1.93904900

C -5.01721800 4.04993000 -1.07041500

H -5.67441200 $4.23657900-1.91312700$
C -3.68140200 4.40531400 -1.07822000

H -3.28349700 $4.90066700-1.95732600$

C -6.96707100 $2.91533300-0.04437400$

H -7.42612100 $3.31609200-0.95087600$

H -7.49810800 3.328835000 .81637500

C -6.96732300 $1.40069900-0.03357300$

C -7.49864600 0.698541001 .04566200

H -7.94195900 1.230140001.88392600

C -7.49864600 -0.69854500 1.04566200

H -7.94195900 -1.23014500 1.88392500

C $-6.96732200-1.40070100-0.03357500$

C -6.44443300 - $0.69339000-1.12298600$

H -6.05911300 -1.22665400 -1.98922700

C -6.44443400 $0.69338900-1.12298500$

H -6.05911300 1.22665400 -1.98922600

C -6.96707000 -2.91533500 -0.04437800

$\mathrm{H}-7.49810700-3.328839000 .81637100$

H -7.42611800 -3.31609300 -0.95088000

N -5.56573700 - $3.44019000-0.00055500$

N $5.56573900-3.44018800-0.00055600$

C - $4.83261600-3.228449001 .11264300$

H -5.34651400 -2.74920000 1.93904500

C -3.49940900-3.56949700 1.15929300

H -2.93980900 -3.34838300 2.06100000

C - $2.87255700-4.130293000 .03378400$

C -3.68140000 -4.40531500 -1.07822400

H -3.28349500 -4.90066700 -1.95733100

C -5.01721600 -4.04993100 - 1.07041900 
H -5.67441000 -4.23658000 -1.91313100

C - $1.40410800-4.324397000 .01094500$

C - $0.69407000-4.650826001 .17514700$

H - $1.22364200-4.921844002 .08387900$

C $0.69407300-4.650825001 .17514700$

H $1.22364500-4.921844002 .08387800$

C $1.40411100-4.324396000 .01094500$

C $0.69422300-4.07184400-1.16908000$

H $1.22083700-3.81375700-2.08276600$

C - $0.69422000-4.07184500-1.16908000$

H - $1.22083600-3.81375800-2.08276500$

C $2.87255900-4.130293000 .03378300$

C $3.49941100-3.569497001 .15929300$

H $2.93981200-3.348385002 .06100000$

C $4.83261900-3.228449001 .11264200$

H 5.34651700 -2.74920100 1.93904500

C $5.01721800-4.04992800-1.07042100$

H $5.67441200-4.23657700-1.91313300$

C $3.68140200-4.40531300-1.07822600$

H $3.28349700-4.90066400-1.95733200$

C $6.96707100-2.91533300-0.04437900$

H $7.42612100-3.31609100-0.95088100$

H $7.49810900-3.328836000 .81637000$

C $6.96732300-1.40069900-0.03357600$

C $7.49864600-0.698542001 .04566000$

H 7.94195900 -1.23014200 1.88392300

C 7.498646000 .698543001 .04566100

H 7.941959001 .230142001 .88392500

C $6.967322001 .40070100-0.03357400$

C $6.444433000 .69339100-1.12298600$

H $6.059113001 .22665600-1.98922700$

C $6.44443400-0.69338800-1.12298700$

H $6.05911400-1.22665200-1.98922900$

C $6.967070002 .91533500-0.04437500$

H 7.498107003 .328838000 .81637300

H 7.42611800 $3.31609400-0.95087700$

\section{NDI}

O $-3.53972600-2.254833000 .00014900$

O $-3.511741002 .29550700-0.00012000$

N-3.52634200 $0.01291400-0.00007300$

C $0.70572500-0.002281000 .00000500$

C $1.39526400-1.23548500-0.00003900$

C $0.69787500-2.42408500-0.00012100$
H $1.25552300-3.35484800-0.00015800$

C $-0.71235700-2.41991800-0.00013200$

H - $1.27609700-3.34709000-0.00017000$

C - $1.40144100-1.22692100-0.00005800$

C - $-2.88968300-1.230302000 .00005000$

C -2.88551000 $1.25671500-0.00007500$

C $-4.98891000-0.021208000 .00002600$

H -5.346045001 .005107000 .00103300$

H -5.34061700 - 0.553763000 .88544300

O $3.539728002 .25483300-0.00018800$

O $3.51173800-2.295508000 .00009900$

N $3.52634300-0.012914000 .00008300$

C - 0.705725000 .002282000 .00000900

C - 1.395264001 .235485000 .00003800

C - 0.697875002 .424085000 .00011900

H - 1.255523003 .354849000 .00014200

C 0.712357002 .419919000 .00014300

H 1.276096003 .347090000 .00018600

C 1.401441001 .226922000 .00008000

C 2.889684001 .230303000 .00001300

C $2.88551000-1.256714000 .00003200$

C $4.988911000 .02120600-0.00002300$

H $5.34604200-1.00511000-0.00107200$

H $5.340618000 .55379100-0.88542200$

H 5.340922000 .551956000 .88635700

H -5.34091500 -0.55199400 -0.88633500

\section{NDI $^{-1}$}

O -3.55097000 -2.25862200 0.00033000

O $3.52176800-2.301547000 .00015800$

N $3.49665000-0.01271400-0.00005500$

C - $2.86394600-1.23874500-0.00008300$

C - $1.40642700-1.22931200-0.00017900$

C - $0.69737600-2.44489600-0.00025200$

H - $1.27069000-3.36618200-0.00033100$

C $0.68272500-2.44911600-0.00026400$

H $1.24976500-3.37415400-0.00029800$

C $1.40058700-1.23807700-0.00016600$

C $0.71548100-0.00225000-0.00015900$

C $2.85927000-1.26570000-0.00001700$

C 4.951076000 .021062000 .00063000

H $5.309572000 .55160800-0.88515100$

H $5.30521000-1.006772000 .00686000$

O $3.550965002 .25865300-0.00016500$

O -3.521770002 .301572000 .00013500$ 
N -3.49664100 0.012714000 .00030700

C $2.864004001 .23878000-0.00021800$

C $1.406429001 .22932600-0.00013400$

C $0.697361002 .44489500-0.00000700$

H 1.270665003 .366188000 .00007700

C - 0.682738002 .449119000 .00002500

H - 1.249775003 .374161000 .00011300

C - $-1.400610001 .23809100-0.00011600$

C - $0.715499000 .00227300-0.00018000$

C - $-2.859294001 .26570600-0.00020400$

C - $-4.95104900-0.021166000 .00008000$

H -5.30928000 - 0.551184000 .88629400

H -5.30530600 $1.00662600-0.00667300$

H 5.307519000 .562760000 .88031900

H -5.30764900 - $0.56343600-0.87918300$

\section{NDI $\subset E B_{B o x}{ }^{4+}$}

O $-4.12930300-0.67817400-0.14306300$

O - $1.986377002 .16436800-2.97309800$

N -3.04154900 $0.62723500-1.65069900$

C $0.61130200-0.150635000 .31546000$

C $0.61141100-0.944124001 .48356700$

C - $0.57299400-1.381405002 .03771100$

H - $0.54139000-1.980384002 .94306100$

C - $1.79862100-1.055521001 .41854100$

H - $2.74170800-1.393525001 .83568700$

C - $1.81501100-0.334943000 .24353800$

C - $3.09057100-0.14866000-0.49734000$

C - $1.907006001 .32203800-2.10729700$

C - $4.284092000 .74259700-2.41552100$

H -4.15806700 $1.52255600-3.16378300$

H -5.10508400 $0.96408900-1.73406700$

O 4.129358000 .678171000 .14406500

O $1.98643600-2.164816002 .97371900$

N $3.04168800-0.627650001 .65143200$

C - $0.611245000 .15071900-0.31442500$

C - $0.611349000 .94409300-1.48259600$

C $0.573067001 .38130000-2.03680200$

H $0.541445001 .98014200-2.94224000$

C $1.798684001 .05546700-1.41760500$

H $2.741799001 .39324600-1.83489200$

C $1.815064000 .33498100-0.24253200$

C 3.090643000 .148582000 .49828300

C $1.90707900-1.322309002 .10808300$
C $4.28432700-0.743443002 .41599400$ H $4.15829400-1.523608003 .16404600$ H $5.10514600-0.964939001 .73430000$ N 5.480279003 .451740000 .08678300 N -5.78384100 3.170600000 .57706300 C 4.877460003 .398692001 .28932100 H 5.518504003 .196787002 .14064900 C 3.516251003 .591584001 .41363900 H 3.081335003 .570693002 .40691000 C 2.727087003 .821040000 .27638900 C $3.399031003 .93638800-0.94964900$ H $2.863141004 .14377000-1.86982400$ C $4.763533003 .74146800-1.01689700$ H $5.315044003 .80639800-1.94834600$ C 1.246168003 .864572000 .35293300 C 0.589063003 .089533001 .31708600 H 1.158841002 .487452002 .01954000 C - 0.795885003 .034358001 .35691100 H - 1.275864002 .392330002 .09063800 C - 1.567043003 .749807000 .43075100 C - $0.913791004 .53494700-0.52902100$ H -1.48522300 $5.13163700-1.23377300$ C $0.475497004 .59473200-0.56300900$ H $0.953256005 .24285200-1.29204500$ C - 3.043678003 .633197000 .47703500 C -3.712736003 .459063001 .69922700$ H -3.18381300 3.520554002 .64380400 C -5.07182700 3.22543900 1.72086900 H -5.62346800 3.075839002 .64242200 C -5.18657900 $3.41709400-0.60633700$ H -5.82669000 $3.39715300-1.48200300$ C $-3.827637003 .65317900-0.68689600$ H -3.38130000 $3.79923100-1.66619300$ C -7.20422600 2.690974000 .61019700 H -7.73454800 $3.19107400-0.20250600$ H -7.63266100 3.028495001 .55642800 C -7.224262001 .183836000 .47066200$ C -6.962501000 .375608001 .58077400$ H -6.83633300 0.817967002 .56596800 C -6.89962900 -1.00417400 1.44388100 H -6.72163500 -1.61737000 2.32402500 C -7.08955200 -1.598613000 .19388700$ C $-7.40043400-0.79844800-0.90385500$ H -7.61258900 -1.24889500 -1.87057800 
C -7.47429500 $0.58713900-0.76498900$

H -7.74841200 1.19564800 -1.62401800

C $-6.93091500-3.093995000 .03566500$

H -7.42931700 - $3.46897800-0.86065400$

H -7.32041600 -3.64394700 0.89523900

N -5.48030500 -3.45170700 -0.08678100

N $5.78390400-3.17080900-0.57807600$

C $-4.87741100-3.39845300-1.28927800$

H -5.51842000 -3.19653300 -2.14063100

C - $3.51617700-3.59117900-1.41352500$

H - $3.08121800-3.57015900-2.40677500$

C - $2.72703900-3.82067200-0.27625200$

C - $3.39904600-3.936203000 .94972900$

H -2.86324700 -4.14360600 1.86995600

C $-4.76358600-3.741442001 .01690300$

H -5.31514000 -3.80650800 1.94832000

C - $1.24612000-3.86409800-0.35281700$

C $-0.58908400-3.08898200-1.31696300$

H - $1.15890500-2.48680600-2.01930000$

C $0.79586000-3.03386100-1.35693600$

H $1.27581400-2.39182600-2.09068100$

C $1.56708100-3.74941800-0.43091200$

C $0.91391300-4.534554000 .52891700$

H $1.48540600-5.131272001 .23359400$

C $-0.47537900-4.594298000 .56303300$

H -0.95308300 -5.24243600 1.29209200

C $3.04371900-3.63299900-0.47745700$

C $3.71261500-3.45951800-1.69982600$

H $3.18352500-3.52131800-2.64429100$

C $5.07174200-3.22607700-1.72177200$

H $5.62329200-3.07695200-2.64346200$

C $5.18678200-3.416719000 .60551300$

H $5.82703500-3.396479001 .48105600$

C $3.82782400-3.652567000 .68638100$

H $3.38156700-3.798057001 .66581500$

C $7.20422900-2.69106900-0.61144300$

H $7.73482100-3.191321000 .20099400$

H $7.63246500-3.02827500-1.55787500$

C $7.22409400-1.18395800-0.47154900$

C $6.96188300-0.37555500-1.58143600$

H $6.83543000-0.81777600-2.56665700$

C $6.898970001 .00419200-1.44428700$

H $6.720666001 .61753100-2.32426700$

C $7.089275001 .59843700-0.19425000$
C 7.400472000 .798098000 .90326400

H 7.612847001 .248384001 .87001200

C $7.47438800-0.587470000 .76414000$

H $7.74880700-1.196097001 .62299100$

C $6.930816003 .09381300-0.03577000$ H 7.429328003 .468570000 .86058400

H $7.320373003 .64384800-0.89526800$ H 4.500488000 .207152002 .91131700

H -4.49992800 - $0.20821000-2.91058700$

NDI $^{-} \subset$ ExBox $^{4+}$

O $4.31401500-0.22283900-0.05200600$

O $-1.78947500-0.84045400-3.50995400$

N -2.91765800 -0.27379900 -1.59989300

C $3.21231900-0.069351000 .48450000$

C $1.94614900-0.04915100-0.24222600$

C $1.93520900-0.23667900-1.63715900$

H $2.88994000-0.29521700-2.15241800$

C $0.73805400-0.37180500-2.31586600$

H $0.70293600-0.55057900-3.38637100$

C - $0.48167900-0.27778700-1.61957500$

C $-0.50767500-0.01774200-0.23544100$

C $-1.73498200-0.49309400-2.34099400$

C -4.18876500 - $0.43203500-2.29071700$

H $-4.77600600-1.21420700-1.80032600$

H -3.98253600 - $0.69227100-3.32625500$

O - 4.096438000 .255443000 .27185500

O 2.039470000 .648261003 .79257900

N 3.132568000 .063016001 .87078700

C - $2.989890000 .06349000-0.24916400$

C - 1.725258000 .142309000 .47068300

C - 1.710185000 .389333001 .85846500

H - 2.661942000 .507167002 .36981000

C - 0.512119000 .469808002 .54510100

H - 0.479297000 .647801003 .61548400

C 0.707718000 .311972001 .86152300

C 0.730745000 .086481000 .46980700

C 1.964256000 .373590002 .60673100

C $4.38237600-0.047732002 .60734500$

H 5.048153000 .787162002 .37112200

H $4.15431000-0.055171003 .67066100$

N -5.59952300 $3.16404600-0.10663300$

N $5.709682003 .08054100-0.24165100$

C $7.177443002 .79479200-0.24944500$

H 7.599160003 .237030000 .65545300 
H $7.601625003 .30650400-1.11571800$ C 5.031692003 .030870000 .92114500 H 5.628716002 .918132001 .81910900 C 3.656930003 .123349000 .95205800 H 3.160467003 .042631001 .91360200 C $2.934543003 .28042200-0.24265400$ C $3.677171003 .35189300-1.43207900$ H $3.195582003 .52070300-2.38767000$ C $5.049389003 .23744900-1.40488600$ H $5.656180003 .28225900-2.30188800$ C $1.460321003 .36161500-0.24965300$ C 0.763172003 .797309000 .88446700 H 1.296587004 .151912001 .76064700 C - 0.622693003 .812908000 .89418800 H - 1.135355004 .181777001 .77659500 C - $1.348379003 .39506500-0.22938100$ C - $0.649812002 .99007100-1.37382400$ H - $1.182146002 .62327200-2.24656000$ C $0.735658002 .97309400-1.38384300$ H $1.245020002 .58575800-2.26002300$ C -2.82356800 $3.33540000-0.19205900$ C -3.51075100 3.165499001 .01813000 H -2.97844200 3.054293001 .95512900 C - 4.884233003 .072842001 .03053500 H -5.44916900 2.908916001 .94097800 C - $4.973295003 .32703500-1.28953600$ H -5.60734200 $3.40472800-2.16574300$ C -3.60010500 $3.41936100-1.35960400$ H - $3.146380003 .58632400-2.32955500$ C -7.08100300 $2.96707400-0.05532500$ H -7.49167500 $3.39063400-0.97393300$ H -7.45558400 3.548953000 .78958700 C -7.37130900 1.494572000 .08501400 C -7.31550200 $0.66979200-1.03970300$ H -7.21628300 1.10310400 -2.03227100 C -7.36540500 - $0.70870400-0.89453000$ H -7.29934200 - $1.34705600-1.77262700$ C - $7.47785500-1.273299000 .37742600$ C -7.64466500 - 0.447515001 .48811100 H -7.80428900 -0.87971100 2.47321100 C -7.58711200 0.935435001 .34271800 H -7.70426600 1.573095002 .21556000 N $5.50653900-3.18027500-0.32908200$ N $-5.78702400-3.018333000 .50882500$
C -7.26211600 -2.75502500 0.55527700

H -7.71743000 - $3.34746300-0.24040700$ H -7.63080300 -3.11961600 1.51691600 C $-5.23853900-3.75659900-0.47835100$ H -5.92683600 - $4.22906100-1.17025000$ C -3.86962000 -3.89109600 - 0.58569100 H -3.47723200 - $4.50812300-1.38569000$ C -3.01944500 -3.25426400 0.33470000 C - $3.63058000-2.533116001 .36926100$ H -3.04450900 -1.98884000 2.09994600 C -4.99946200 -2.42050700 1.42400900 H -5.50035700 -1.81636700 2.17007100 C - $1.54726300-3.311586000 .22333500$ C - $0.93120000-3.53943100-1.01218500$ H - $1.52147000-3.66414800-1.91525100$ C $0.45306200-3.56034100-1.11622500$ H $0.89431900-3.76092500-2.08652600$ C $1.25885400-3.340403000 .00753200$ C $0.63859300-3.110433001 .24415200$ H $1.22801600-2.896415002 .13008000$ C - $0.74124300-3.102243001 .35199200$ H -1.18371800 -2.93919500 2.32877100 C $2.73264400-3.31449800-0.10771000$ C $3.36242200-3.06912900-1.33731700$ H $2.78884800-2.88716300-2.23723900$ C $4.73397200-2.99780000-1.41663600$ H $5.25215200-2.78739000-2.34473700$ C $4.93984900-3.432643000 .86607800$ H $5.61718300-3.586766001 .69890800$ C $3.56994600-3.513871001 .00198300$ H $3.16981600-3.755510001 .97952700$ C $6.98183900-2.96360200-0.43660100$ H $7.44708300-3.498422000 .39360600$ H $7.30832800-3.42624900-1.37061500$ C $7.25529400-1.48171000-0.39871700$ C $7.39926800-0.829830000 .82416800$ H $7.46297200-1.401880001 .74689800$ C 7.454591000 .558016000 .87075700 H 7.569314001 .059788001 .82884700 C $7.358270001 .29862300-0.30637000$ C $7.304724000 .64304100-1.53587400$ H $7.298553001 .21170200-2.46244800$ C $7.25726300-0.74350500-1.58213700$ H 7.22094400 -1.24710300 -2.54499200 
H -4.76235700 $0.49673100-2.22622300$

H $4.89774200-0.961085002 .30065900$

\section{NDI $^{2-}$}

O -3.57106900 - $2.26531600-0.00014100$

O -3.54026700 $2.31134000-0.00004500$

N -3.47509600 0.012229000 .00001700

C $0.72566000-0.00197900-0.00000700$

C $1.41021300-1.24144600-0.00003000$

C $0.67176200-2.47606400-0.00004300$

H $1.24759500-3.39723400-0.00005100$

C - $0.68566700-2.47193600-0.00005800$

H - $1.26767900-3.38938600-0.00008300$

C - $1.41498800-1.23270400-0.00003000$

C - $2.84697800-1.24799300-0.00007000$

C - 2.841952001 .275346000 .00006800

C - $4.92280900-0.021600000 .00006800$

H -5.27105000 1.009333000 .00110500

H -5.28576800 - 0.564052000 .87937800

O 3.571069002 .265316000 .00017000

O $3.54026700-2.311340000 .00003400$

N $3.47509600-0.01222900-0.00001700$

C - 0.725660000 .001979000 .00000200

C - 1.410213001 .241446000 .00003800

C - 0.671762002 .476064000 .00005000

H - 1.247595003 .397234000 .00007100

C 0.685667002 .471936000 .00004600

H 1.267679003 .389386000 .00005900

C 1.414988001 .232704000 .00001300

C 2.846978001 .247993000 .00001500

C $2.84195200-1.27534600-0.00002100$

C $4.922809000 .02160000-0.00006700$

H $5.27105000-1.00933300-0.00105300$

H $5.285768000 .56401100-0.87940100$

H 5.286040000 .562221000 .88028700

H -5.28604000 - $0.56217900-0.88031100$

*NDI*

O $3.56283700-2.26067000-0.00037500$

O $-3.53567400-2.29945000-0.00007000$

N -3.53958000 $-0.01113800-0.00055000$

C $2.88412800-1.23735000-0.00014200$

C $1.42490900-1.23165700-0.00013900$

C $0.70822300-2.42347100-0.00020300$

H $1.26254800-3.35737400-0.00024300$
C $-0.69416900-2.42759800-0.00020800$

H - $1.24245200-3.36493500-0.00025000$

C $-1.41922500-1.23961200-0.00020100$

C $-0.69077100-0.00207700-0.00012100$

C - $2.87858300-1.26220000-0.00030300$

C $-4.988659000 .01948800-0.00013000$

H -5.35999300 0.543674000 .88595400

H -5.33766500 - $1.01089300-0.00454000$

O -3.56283600 2.26067000 0.00061200

O 3.535670002 .299454000 .00033400

N 3.539581000 .011138000 .00049300

C -2.88412800 1.237350000 .00002200

C - $1.424909001 .23165700-0.00001800$

C - 0.708223002 .423471000 .00011800

H - 1.262549003 .357374000 .00020800

C 0.694169002 .427598000 .00011000

H 1.242452003 .364935000 .00019000

C 1.419225001 .239613000 .00002000

C $0.690771000 .00207700-0.00007200$

C 2.878583001 .262201000 .00011200

C $4.98866000-0.019492000 .00039700$

H $5.36021300-0.54337300-0.88578200$

H 5.337671001 .010884000 .00522000

H -5.35967500 $0.55172100-0.88140600$

H $5.35945200-0.552035000 .88157500$ 